\title{
DNA methylation in epigenetic inheritance of metabolic diseases through the male germ line
}

\author{
Louise Ruby Høj Illum', Stine Thorhauge Bak ${ }^{1,2}$, Sten Lund ${ }^{2}$ and Anders Lade Nielsen ${ }^{1}$ \\ 'Department of Biomedicine, Aarhus University, Aarhus, Denmark \\ 2Department of Clinical Medicine, Endocrinology and Diabetes, Aarhus University Hospital, Aarhus, Denmark \\ Correspondence should be addressed to A L Nielsen: aln@biomed.au.dk
}

\begin{abstract}
The global rise in metabolic diseases can be attributed to a complex interplay between biology, behavior and environmental factors. This article reviews the current literature concerning DNA methylation-based epigenetic inheritance (intergenerational and transgenerational) of metabolic diseases through the male germ line. Included are a presentation of the basic principles for DNA methylation in developmental programming, and a description of windows of susceptibility for the inheritance of environmentally induced aberrations in DNA methylation and their associated metabolic disease phenotypes. To this end, escapees, genomic regions with the intrinsic potential to transmit acquired paternal epigenetic information across generations by escaping the extensive programmed DNA demethylation that occurs during gametogenesis and in the zygote, are described. The ongoing descriptive and functional examinations of DNA methylation in the relevant biological samples, in conjugation with analyses of noncoding RNA and histone modifications, hold promise for improved delineation of the effect size and mechanistic background for epigenetic inheritance of metabolic diseases.
\end{abstract}

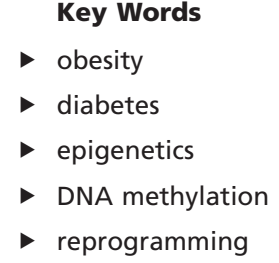

Journal of Molecular Endocrinology (2018) 60, R39-R56

\section{Introduction}

Metabolic diseases are mainly attributed to lifestyle, but the importance of heritability is evident as well. Mendelian inheritance of risk genes for metabolic diseases cannot fully explain the observed heritability. Accordingly, a new perspective has become the focus of attention: the inheritance of environmentally induced epigenetic changes in gametes representing a risk factor for the offspring to acquire metabolic diseases. Epigenetics can descriptively and mechanistically explain mitotic and meiotic inheritance of a phenotype without requiring an underlying change in genetics. Epigenetics play vital roles in normal development, as well as in human disease etiology, by being functionally involved in the control of the cellular gene expression program (e.g. in response to given environmental conditions).
While the contribution of epigenetics to the inheritance of Mendelian traits in mammals seems minor relative to genetics, the quantitative and qualitative importance of epigenetics in complex diseases (e.g. metabolic diseases) is not fully elucidated and might be underestimated. It is widely accepted that epigenetic reprogramming occurs both during gametogenesis and immediately following fertilization. However, evidence exists that epigenetic marks at specific genome positions can escape such reprogramming, and thereby supports the notion that epigenetic changes can be transferred between generations (reviewed in Wu \& Suzuki 2006, Perera \& Herbstman 2011, Pembrey et al. 2014, Wei et al. 2015). It is well established that environmental exposure of the mother can affect the disease risk of the offspring. 
A deoxycytidine (C) 5-methyl deoxycytidine $(5 \mathrm{mC})$

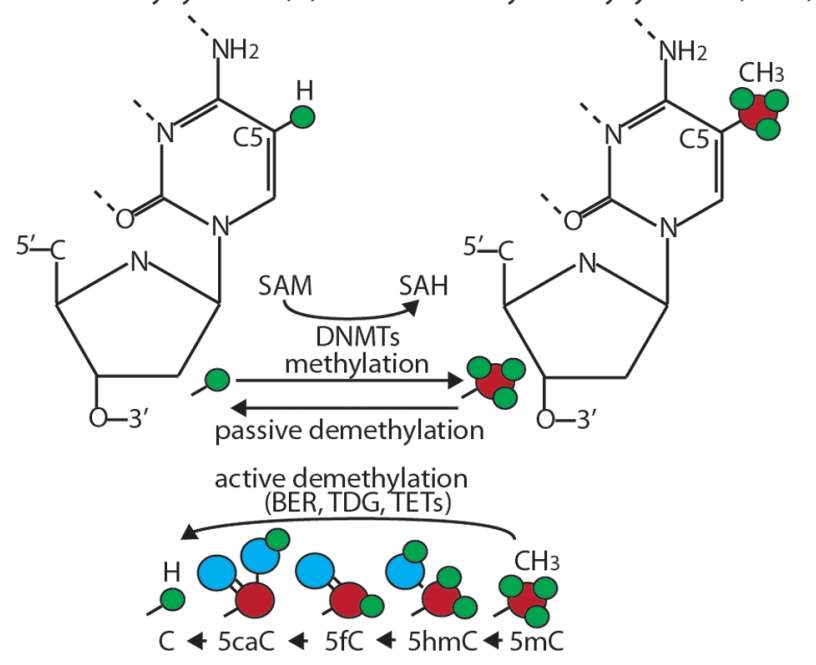

B

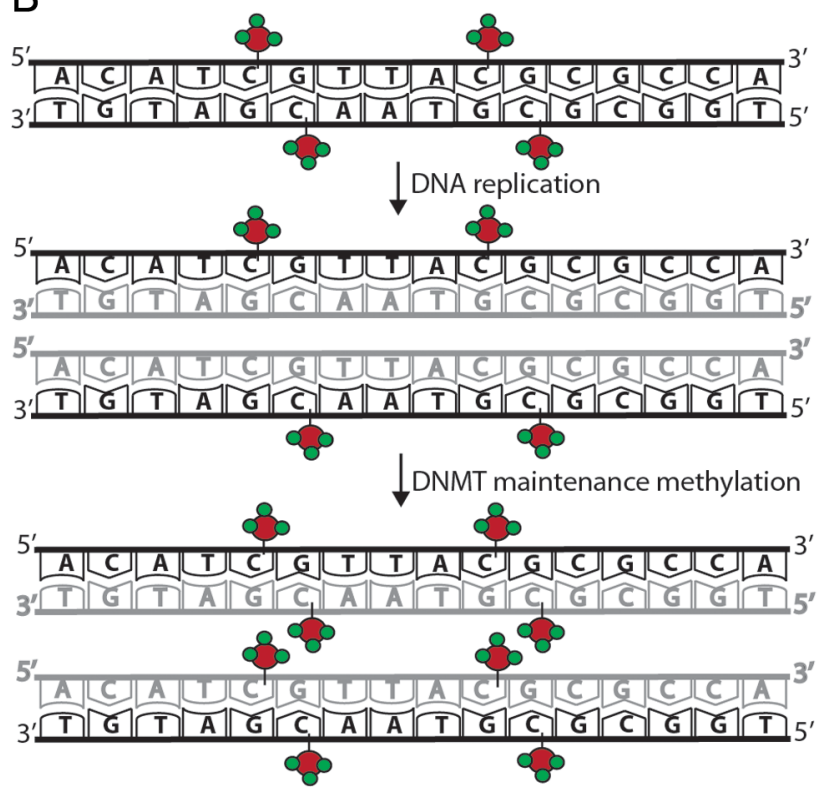

Figure 1

Basic principles of DNA methylation. (A) Schematic illustration of reversible cytosine methylation to generate $5 \mathrm{mC}$. The methylation process depends on DNMTs and conversion of the methyl group donor SAM to SAH. The demethylation process can involve both passive demethylation and active demethylation processes requiring TET proteins, TDG, and BER. In the active process, $5 \mathrm{mC}$ can be converted to the intermediates $5 \mathrm{hmC}, 5 \mathrm{fC}$ and $5 \mathrm{caC}$ before ending up as cytosine. (B) Maintenance of DNA methylation patterns following DNA replication. As a result of DNA replication, the newly generated double-stranded DNA will be hemi-methylated with the original template strands maintaining the original methylation pattern (black strands) and the new strands without methylation (gray strands). The symmetrical nature of $\mathrm{CpG}$ sites ensures that hemi-methylated DNA can direct the original pattern of methylation to the new DNA through the action of DNMTs with DNMT1 considered the most prominent maintenance DNMT. A full colour version of this figure is available at https://doi.org/10.1530/JME-17-0189.
However, it has become clear that the offspring's disease risk is also influenced by paternal exposures illustrated by epigenetic inheritance of e.g. metabolic diseases (reviewed in Curley et al. 2011, Soubry et al. 2014, Rando 2016). When interpreting results concerning epigenetic inheritance, several critical questions should be kept in mind: the effect size of the perceived environmentally induced epigenetic inheritance; the evidence that epigenetic changes are indeed transmitted through the germ line and do not represent erased and re-established epigenetic marks and the evidence that epigenetic rather than genetic changes have arised from a given environmental exposure. Per definition, transmission of changes in epigenetics can be intergenerational or transgenerational (Heard \& Martienssen 2014). When an individual (the F0 generation) is exposed to an environmental factor, the germ line (representing the future F1) is exposed as well. Inheritance of an induced epigenetic change and associated phenotype to F1 is then defined as intergenerational. Only if the epigenetic change and associated phenotype are also present in F2, and eventual subsequent generations without requiring further exposure, the epigenetic inheritance is defined as transgenerational. An exception to this general definition is when females are exposed during pregnancy; then the fetus, as well as the germ line of the fetus (the future F2), are exposed simultaneously. In this instance, inheritance of the epigenetic change and associated phenotype to F1 and F2 is considered intergenerational. Only if the epigenetic change and associated phenotype are present in F3, and eventual subsequent generations without requiring further exposure, the epigenetic inheritance is considered transgenerational. The term epigenetic inheritance is in this review covering both intergenerational and transgenerational inheritance paradigms.

The relationship between defined environmental exposures, epigenetic changes in the male germ line and increased metabolic disease risk will be the main subject of this review. The review also includes a presentation and discussion of the windows of susceptibility for epigenetic inheritance through the male germ line. While the review focuses on DNA methylation, we also acknowledge the importance of non-coding RNA (ncRNA) (i.e. microRNA (miRNA)- and transferRNA (tRNA)-derived small molecules), histone modifications and histone variants, chromatin-associated proteins and chromatin remodeling. Finally, the potential for improving diagnostics and treatment of metabolic diseases in the future based on the rapidly expanding knowledge of DNA methylation mechanisms is briefly discussed. 


\section{DNA methylation: the basic toolbox}

DNA methylation is tightly associated with time and spatial regulation of gene expression, X-chromosome inactivation, parental imprinting, silencing of repetitive elements, cell differentiation and human diseases. A variety of robust identification methods for DNA methylation exists, and for a guide, we refer to recent comprehensive reviews (Tirado-Magallanes et al. 2016, Yong et al. 2016). In the DNA methylation chemical process, a $\mathrm{CH} 3$ group is attached to the $\mathrm{C} 5$ of a cytosine residue, thereby creating 5 -methylcytosine (5mC) (Fig. 1A). DNA methylation is effectuated by DNA methyltranferases (DNMTs) and the majority of DNA methylations in mammals occur in the context of $\mathrm{CpG}$ dinucleotides. The DNMT family includes DNMT1, DNMT3A, DNMT3B and DNMT3L, with the last now categorized as a catalytically inactive DNMT family member enhancing DNMT3A and DNMT3B enzymatic activity (Jurkowska et al. 2011). In a highly generalized scenario, DNMT3A and DNMT3B perform the de novo methylation of DNA, which is vital, for example, during early development (Okano et al. 1999, Jones \& Liang 2009, Jurkowska et al. 2011). DNMT1 primarily functions to maintain specific DNA methylation patterns in connection with cell division (Fig. 1B) (Jones \& Liang 2009). Mice depleted of DNMT1, or the essential cofactor UHRF1 (also called NP95, ICBP90 or RNF106), display embryonic lethality (Li et al. 1992, Sharif et al. 2007). DNA demethylation can be either passive, a process arising because of DNA replication without coupled de novo methylation, or active, a process involving the intermediates 5-hydroxymethylcytosine $(5 \mathrm{hmC})$, 5-formylcytosine (5fC) and 5-carboxycytosine (5caC) (Fig. 1A) (Wu \& Zhang 2014). Active demethylation depends on demethylase protein complexes such as the ten-eleven translocation (TET) family of proteins (TET1, TET2, and TET3), thymine DNA glycosylase (TDG) and base-excision repair (BER) (Kohli \& Zhang 2013).

Three general schemes by which DNA methylation may influence the regulation of gene expression are summarized in Fig. 2 (Jones 2012). Transcriptionally active genes usually manifest hypomethylation surrounding the transcriptional start site. However, the complexity of the linkage between DNA methylation and transcription is illustrated by genes with promoters having low CpG content and hypermethylation being transcriptionally active e.g., during gametogenesis (Weber et al. 2007, Meissner et al. 2008, Hammoud et al. 2014). Moreover, transcriptionally active genes are normally hypermethylated in the gene body (Ball et al. 2009,
Lister et al. 2009). This methylation is thought to block the initiation of spurious transcription, thereby avoiding the generation of aberrant RNAs (Huh et al. 2013, Baubec et al. 2015, Neri et al. 2017). In addition, exons display higher methylation levels than introns, also linking
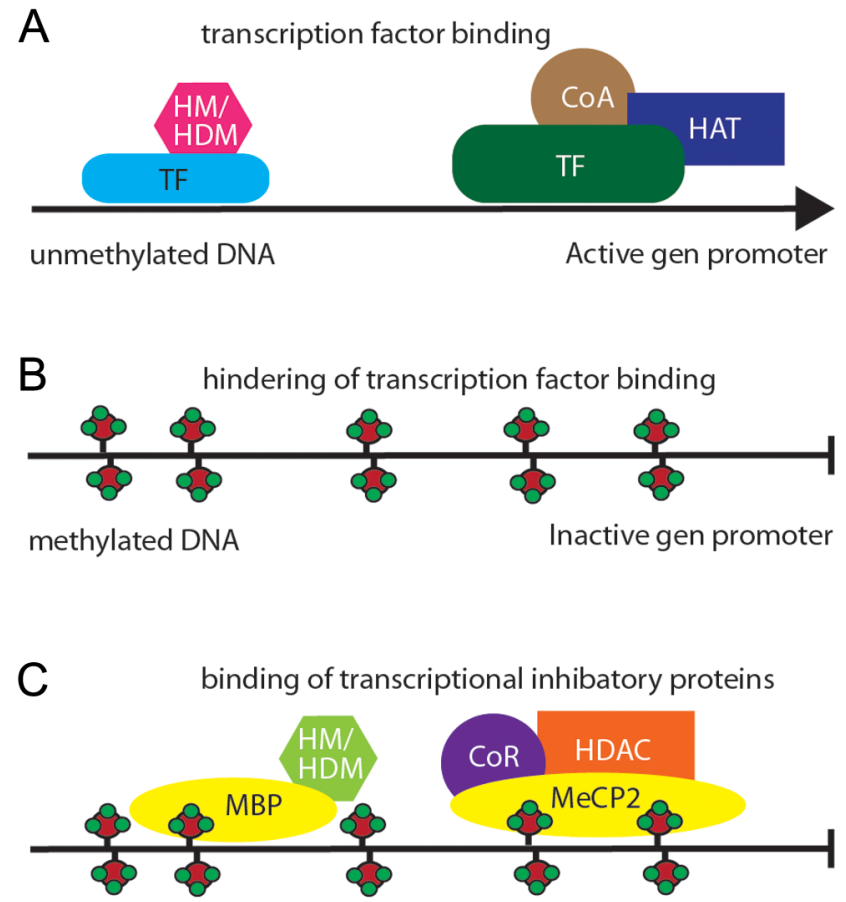

methylated DNA

Inactive gen promoter

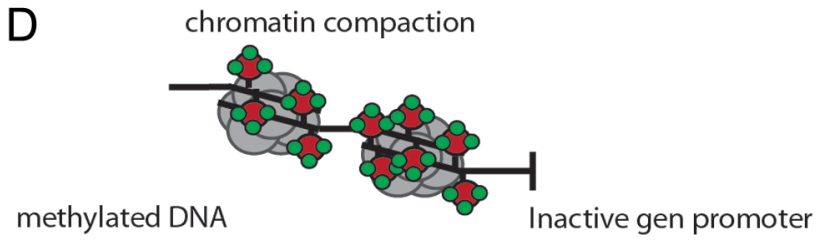

\section{Figure 2}

Schematic mechanisms of transcriptional regulation through promoter DNA methylation. (A) For a transcriptionally active promoter, the recruitment of transcription factors (TFs) results in an open chromatin structure with relative nucleosome depletion and transcriptional coactivator ( $\mathrm{COA}$ ) presence. This outcome is achieved through protein complexes with e.g. histone acetylase (HAT), histone methylation (HM), and histone demethylation (HDM) activities towards histone tail residues. (B) Following DNA methylation of the promoter, TF binding is hindered by blocking of the specific recognition sequences, and this resulting in decreased promoter activity. (C) Following DNA methylation of the promoter, $5 \mathrm{mC}$ residues recruit MeCP2 and members of the MBP family. These proteins can take part in protein complexes mediating transcriptional repression depending on histone deacetylase (HDAC), HM, and HDM activities towards histone tail residues, as well as recruit transcriptional corepressors (CoR). (D) Following DNA methylation of the promoter, chromatin remodeling and compaction results in a repressive transcriptional context. Note that scenarios B, C and D are not mutually exclusive. A full colour version of this figure is available at https://doi. org/10.1530/JME-17-0189. 
DNA methylation to post-transcriptional RNA processing (Brown et al. 2012).

The human genome includes around 56 million CpG sites, and $60-80 \%$ of these are methylated (Laurent et al. 2010). Note that less than $20 \%$ of all CpG sites display methylation differences between tissues (Ziller et al. 2013). Throughout the genome, CpG sites are unevenly distributed. CpG islands (CGIs) are defined as regions with a size of at least $550 \mathrm{bp}$ and an observed-to-expected $\mathrm{CpG}$ ratio above 0.65 (Gardiner-Garden \& Frommer 1987, Takai \& Jones 2004, Deaton \& Bird 2011). Approximately 70\% of the human genes have promoter CGIs either extensively demethylated or methylated (Ioshikhes \& Zhang 2000, Bird 2002, Saxonov et al. 2006). CGI shores, defined as the $2 \mathrm{~kb}$ sequences flanking a CGI, have more dynamic DNA methylation patterns than their corresponding CGIs (Doi et al. 2009, Irizarry et al. 2009, Edgar et al. 2014). Beyond CGI shores, CGI shelves and open sea, CpG sites exist (Bibikova et al. 2011, Sandoval et al. 2011).

While the majority of DNA methylations in mammals occur in the context of $\mathrm{CpG}$ dinucleotides, their presence is not mandatory, and non-CpG methylation has been observed in a variety of cell types including male germ cells. Non-CpG methylation is involved in the regulation of gene expression, is sensitive towards environmental inputs and can be inherited through several generations in mice (Ramsahoye et al. 2000, Grandjean et al. 2007, Barres et al. 2009, Lister et al. 2009, Yan et al. 2011, Ichiyanagi et al. 2013). Interestingly, (re)establishment of non-CpG methylation after cell division is linked to the methylation status of neighboring $\mathrm{CpG}$ sites and is mediated by either DNMT3A or DNMT3B in complex with DNMT3L (Ramsahoye et al. 2000, Grandjean et al. 2007, Barres et al. 2009, Arand et al. 2012, Ichiyanagi et al. 2013). Since the functional role of non-CpG methylation in epigenetic inheritance remains to be explored, the focus of this review will be on CpG methylation.

\section{Epigenetic reprogramming, escapees and windows of susceptibility}

There are four windows of susceptibility, which have major importance for epigenetic inheritance of acquired paternal epigenetic changes: (1) paternal primordial germ cell (PGC) development, (2) prospermatogonia stages, (3) spermatogenesis and (4) during preimplantation (Fig. 3) (Soubry et al. 2014, Ly et al. 2015). While the literature is most substantiated concerning the epigenetic reprogramming for mice gametogenesis, the overall mechanisms are relatively similar in humans.
For an extensive review concerning the relatedness and differences between human and mouse reprogramming we refer to study by Tang et al. (2016).

Twice during the mammalian life cycle, epigenetic marks undergo extensive reprogramming. CpG site methylation, both developmentally programmed and environmentally acquired, is largely reprogrammed during early gametogenesis and in the zygote immediately after fertilization (Guibert et al. 2012, Saitou et al. 2012, Seisenberger et al. 2012, Kagiwada et al. 2013, Ohno et al. 2013, Messerschmidt et al. 2014, Smith et al. 2014, Guo et al. 2015, Tang et al. 2015). Reprogramming consists of genome-wide erasure of most DNA methylation followed by the establishment of a novel set of DNA methylation marks (Morgan etal. 2005). The erasure of DNA methylation during reprogramming is extensive (particularly in PGCs), but some DNA methylation persists and paves the way for possible epigenetic inheritance. While differential methylated regions (DMRs) for imprinted genes with a gender-dependent predefinition to possess DNA methylation in offspring can be protected from the DNA demethylation process that occurs immediately after fertilization, escapees represent genomic regions protected from reprogramming-associated demethylation during both the PGC and preimplantation stages (Marcho et al. 2015, Canovas \& Ross 2016, Tang et al. 2016, Voon $\&$ Gibbons 2016). Most escapees are associated with retrotransposable elements (e.g., intracisternal A particle (IAP) elements in mice and SINE7-VNTR-ALU (SVA) elements in humans (Lane et al. 2003, Tang et al. 2015)). Specifically, evolutionarily new and potentially hazardous retrotransposable elements are identified as escapees, and the developmentally maintained methylation could be functionally linked to assure the continued transcriptional silencing (and thus maintenance) of genomic integrity. In addition, some subtelomeric regions (Guibert et al. 2012), pericentromeric satellite repeats (Tang et al. 2015) and single-copy loci (Guibert et al. 2012, Seisenberger et al. 2012, Hackett et al. 2013, Tang et al. 2015, 2016) are also described as escapees; a more detailed discussion of singlecopy escapee loci is included in subsequent sections.

\section{The first window of susceptibility: PGC development}

In male mice, PGCs are specified in the postimplantation epiblast. The epiblast displays DNA hypermethylation and is primed for lineage differentiation. The PGC epigenomes of developing male fetuses are susceptible to gestational exposures of their mothers as exemplified by experiments treating pregnant rodent mothers with 

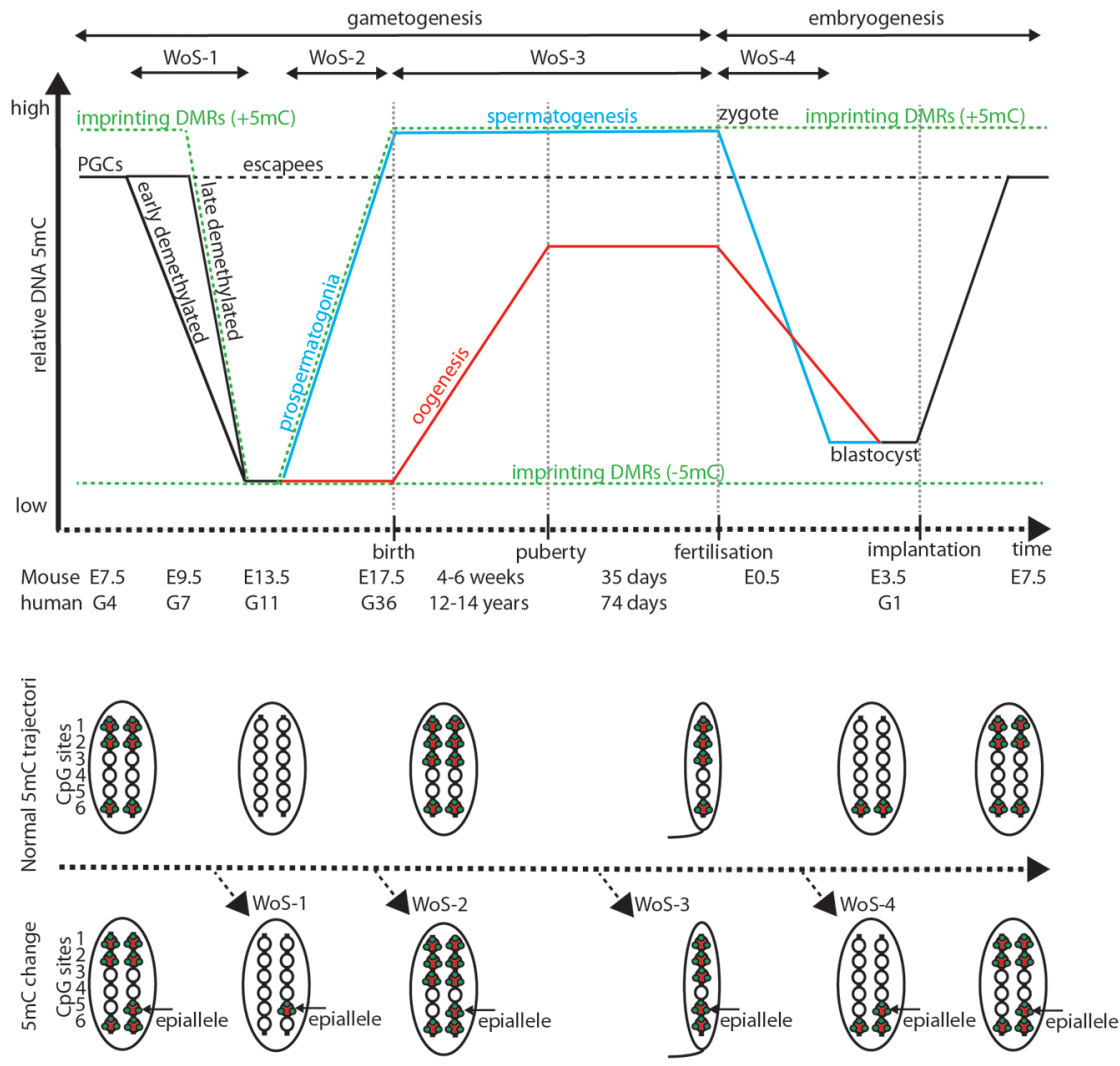

\section{Figure 3}

Cycles of DNA methylation through development. Relative global DNA methylation levels at various developmental times are illustrated. Escapees for DNA methylation remodeling in the male genome are illustrated by dotted lines. Cells display two major waves of demethylation. One wave occurs in PGCs (early and late demethylation) when most methylation is cleared including imprinted regions, with the notable exception of some repeat regions and single copy loci. The genome is subsequently remethylated in a gender-specific manner. The next wave of demethylation occurs during the preimplementation period, with timing differences for paternal and maternal DNA. Imprinting DMRs can escape this remodeling. Key time points for mice and the corresponding time points identified in humans are shown. The windows of susceptibility (wos) defined by Soubry et al. (2014) for acquirements of DNA methylation alterations are indicated. The lower section of the figure illustrates the epigenetic reprogramming of a model genomic segment including $6 \mathrm{CpG}$ sites, and the escape of remodeling for an exposuremediated gain in DNA methylation, generating an epiallele, in the male germ line. White and colored circles indicate $\mathrm{CpG}$ sites without and with methylation, respectively. A full colour version of this figure is available at https://doi. org/10.1530/JME-17-0189. the fungicide vinclozolin (Anway et al. 2005, GuerreroBosagna et al. 2010). Reprogramming in the epiblast facilitates gametogenesis and is required for the erasure of parental epigenetic memories. In the male embryo, the epigenetic reprogramming of the PGCs migrating to the genital ridge between E7.5 and E13.5 results in a genome-wide erasure of DNA methylation (Guibert et al. 2012, Saitou et al. 2012, Messerschmidt et al. 2014, Smith et al. 2014, Guo et al. 2015). The global DNA methylation level decreases from $70 \%$ in the epiblast to approximately 4-10\% in E13.5 PGCs (Seisenberger et al. 2012, Kobayashi et al. 2013). This decrease represents the lowest naturally occurring extent of DNA methylation. Escapees will, by definition, remain resistant to this wave of DNA methylation erasure (Guibert et al. 2012, Tang et al. 2015). To achieve hypomethylation, the expression of DNMT3A, DNMT3B and the DNMT1 cofactor UHRF1 is largely repressed (Kurimoto et al. 2008, Seisenberger et al. 2012, Kagiwada et al. 2013, Magnusdottir et al. 2013, Ohno et al. 2013, Arand et al. 2015). Given the impossibility of genome-wide de novo and maintenance methylation without the presence of sufficient DNMT enzymatic activity, the consequence is replication-coupled, passive, DNA demethylation (Kagiwada et al. 2013, Ohno et al. 2013). From E9.5 to E13.5 enzymatic-coupled, active,
DNA demethylation is also present in PGCs (Yamaguchi et al. 2013a, Gkountela et al. 2015, Guo et al. 2015, Tang et al. 2015). This active demethylation requires TET1 (and to some extent TET2) activity and involves the enzymatic oxidation of $5 \mathrm{mC}$ to $5 \mathrm{hmC}$ and a subsequent final conversion to cytosine through intermediates (Fig. 1A) (Hajkova 2011, Guibert et al. 2012, Seisenberger et al. 2012, Yamaguchi et al. 2012, 2013b, Dawlaty et al. 2013, Hackett et al. 2013, Kagiwada et al. 2013, Kobayashi et al. 2013). While passive demethylation seems responsible for overall global demethylation, some locus-specific effects are accomplished through active demethylation (Yamaguchi et al. 2012, 2013b, Dawlaty et al. 2013). This is exemplified by imprinting DMRs and germ linespecific genes being protected from demethylation until E9.5 (late demethylation, Fig. 3) (Seisenberger et al. 2012, Messerschmidt et al. 2014). Moreover, DNA demethylation in PGCs is associated with a global reorganization of the chromatin structure, which is accompanied by alterations in histone modification patterns. This reorganization represents one explanation for the observed genomic integrity and lack of extensive genome-wide transcription following hypomethylation of the genome during PGC reprogramming (Guibert et al. 2012, Gkountela et al. 2015, Tang et al. 2015). Moreover, maintenance 
of DNA methylation in escapees can contribute to this stabilization of genomic integrity and silencing of aberrant transcription (Guibert et al. 2012, Tang et al. 2015).

The genomic features predefining certain genomic regions to potentially be escapees are not yet fully clarified. The repression of DNMT3A, DNMT3B and UHRF1 expression in PGCs during the process of DNA demethylation is accompanied by a nuclear expression of DNMT1 (Kagiwada et al. 2013, Gkountela et al. 2015, Tang et al. 2015). Traditionally, DNMT1 is defined as the maintenance DNMT, but this generalization is contradicted by observations that DNMT1 also possesses de novo methylation activity in vitro and in vivo (Biniszkiewicz et al. 2002, Goyal et al. 2006, Arand et al. 2012). This suggests the intriguing possibility that DNMT1 can confer and maintain the DNA methylation of escapee loci in a UHRF1independent manner (Tang et al. 2016). Additionally, escapees are enriched with the repressive histone mark H3K9me3 as well as the chromatin factor TRIM28 (also called KAP1 or TIF1 $\beta$ ). TRIM28 is a transcriptional co-repressor protein that can be recruited sequence-specifically to the genome through KAP1-krupplel-associated box zinc finger proteins (KRAB-ZFPs) or H3K9me3 interactions bridged by the heterochromatin protein 1 (HP1) family members (Tang et al. 2015). Notably, TRIM28 can form protein complexes, which include (in addition to KRAB-ZFPs) DNMT1, HP1 and the SETDB1 histone methyltransferase. The protein complex possesses heterochromatin formation capacity and transcriptional repressor activity towards, for example, SVA and IAP elements (Tan et al. 2013, Jacobs et al. 2014, Wolf et al. 2015). Thus, such genomic recruitment of DNMT1 activity to specific escapees can mechanistically substitute for DNMT1 recruitment to methylated chromatin through UHRF1 not expressed at this developmental time (Sharif et al. 2007). The KRAB-ZFP families comprise more than 400 members in mice and humans, and several KRAB-ZFPs are expressed in PGCs and thus represent one candidate mechanism for the site-specific recruitment of DNMT activity to repetitive and single-copy escapee loci (Tang et al. 2015).

\section{The second and third windows of susceptibility: prospermatogonia stages and spermatogenesis}

New DNA methylation patterns are established following E13.5 in the mitotically arrested prospermatogonia; these patterns are essential in preparing for functional prospermatogonia development (Kato et al. 2007, Kobayashi et al. 2013, Singh et al. 2013). Global methylation levels increase to approximately 50\% in
E16.5 prospermatogonia (Singh et al. 2013). Note that in the paternal lineage, maternally imprinting DMRs should specifically escape remethylation, whereas paternally imprinting DMRs should become methylated (Fig. 3). During both the erasure of DNA methylation and the later establishment of new DNA methylation patterns, the epigenome of the germ cells in the male fetus is susceptible to maternal gestational exposures (Radford et al. 2014). This susceptibility raises the potential for exposuremediated defaults during both the DNA demethylation in PGCs and reestablishment of DNA methylation in prospermatogonia and spermatogenesis. The latter can be exemplified in genomic regions, which in principle should be protected from the DNA methylation machinery but become subject to DNA methylation, or failure to acquire DNA methylation of paternally imprinting DMRs; both scenarios create aberrant epigenetic patterns. If these aberrant DNA methylation patterns are stably maintained during the remaining steps of spermatogenesis, they will exist in offspring at least immediately after conception and thus represent a second window of susceptibility.

Differences in DNA methylation are evident between the mitotically arrested prospermatogonia and the derived mitotic, meiotic and postmeiotic germ cells (Oakes et al. 2007, Marques et al. 2011, Smallwood et al. 2011, Kobayashi et al. 2012, Niles et al. 2013, Molaro et al. 2014, Tseng et al. 2015). In addition, during spermatogenesis, the chromatin structure in the cells and the expression pattern of ncRNA are dramatically remodeled (Ro et al. 2007, Yan et al. 2007, Song et al. 2011, Shirakata et al. 2014). The extensive time from prospermatogonia to final mature sperm cell (decades in humans) represents a risk for DNA methylation changes to accumulate. This period (during prepuberty and adult life) represents the third window of susceptibility to environmental factors that can induce epigenetic changes and be manifested in mature spermatocytes. Notably, while prospermatogonia expansion in mice occurs immediately after birth, in humans, a short burst of proliferation after birth is followed by relative quiescence until two years before puberty when massive prospermatogonia proliferation initiates. This difference provides one explanation for epidemiological results pointing to the male prepubertal period as sensitive to acquiring heritable responses to environmental exposures.

\section{The fourth window of susceptibility: preimplantation}

In order for a spermatozoa with acquired abnormal DNA methylation to sustain this abnormality throughout 
embryogenesis, the established aberrant methylation pattern needs to withstand the DNA methylation reprogramming that occurs during preimplantation. Both sperm and oocytes contain parent-of-origin-specific DNA methylation patterns, and the two haploid genomes accordingly present distinct epigenetic signatures at fertilization. Mouse and human sperm cells display a higher proportion of CpG site methylation (90\%) than oocytes do (40\%) (Howlett \& Reik 1991, Santos et al. 2002, Smith et al. 2012, Guo et al. 2014). During late spermatogenesis, histones are replaced by protamines, and this substitution is important to achieve the compaction of the chromatin necessary to protect the sperm DNA during fertilization (Miller et al. 2010). After fertilization, protamines in the paternal genome are replaced by maternally derived acetylated histones. However, in mature spermatocytes, histone-bound genomic regions (including imprinting DMRs) are present (approximately 1\% in mice and 10\% in human genomes), and these regions remain histonebound throughout fertilization (Hammoud et al. 2009, Brykczynska et al. 2010). This transference also leaves room for histone-based epigenetic inheritance through the male germ line. For the first approximately $24 \mathrm{~h}$ after fertilization, the parental genomes remain physically separated in paternal and maternal pronuclei. In the newly established zygote, the parental genomes undergo an asymmetric demethylation in the early blastocyst stage, followed by a lineage-specific reacquisition of DNA methylation. Although genomic remethylation will not be further addressed in this review, the existence of protection against methylation for imprinting DMRs, which specify maternal imprinting on the paternal genome of the embryo should be noted (Fig. 3) (for review Monk 2015). Moreover, gestational exposures potentially affect both the demethylation and remethylation processes, leaving room for epigenetic inheritance through this fourth window of susceptibility.

For the paternally derived genome, DNA demethylation starts after the protamine to histone substitution (Santos et al. 2002). The demethylation is not as extensive as during PGC reprogramming, and in addition to escapees, imprinting DMRs will avoid demethylation (Lane et al. 2003, Branco et al. 2008, Cirio et al. 2008, Hirasawa et al. 2008). To date, 38 germ linederived imprinting DMRs with maintained, lifelong, allelic methylation have been described in humans and 28 in mice (Kobayashi et al. 2012, Proudhon et al. 2012, Xie et al. 2012, Court et al. 2014). While the demethylation of the paternal genome has been viewed as a division independent, actively mediated process, the delayed demethylation of the maternal genome utilizes a passive, replication-dependent process. It is now clear, however, that the paternal genome demethylation employs both a rapidly acting active demethylation mechanism dependent on TET3 activity and a passive replication-dependent demethylation mechanism (Mayer et al. 2000, Oswald et al. 2000, Guo et al. 2014, Shen et al. 2014). Notably, the decline in $5 \mathrm{mC}$ in the paternally derived genome is accompanied by a prominent increase in $5 \mathrm{hmC}$ and less prominent increases in $5 \mathrm{fC}$ and $5 \mathrm{caC}$ (Gu et al. 2011, Inoue \& Zhang 2011, Iqbal et al. 2011, Wossidlo et al. 2011, Zhu et al. 2017). TET3 is also present in the maternal pronucleus, but $5 \mathrm{mC}$ is largely protected from active demethylation (Guo et al. 2014, Peat et al. 2014, Shen et al. 2014, Wang et al. 2014, Zhu et al. 2017). The PGC7 (also called STELLA or DPPA3) protein, which is genomically recruited through $\mathrm{H} 3 \mathrm{~K} 9 \mathrm{me} 2$, is a candidate to mediate protection of $5 \mathrm{mC}$ in the maternal genome against active demethylation (Nakamura et al. 2007, 2012, Wossidlo et al. 2011, Bian \& Yu 2014). Also in the paternal pronucleus, PGC7 is involved in protecting certain genomic regions (including imprinting DMRs) from demethylation through TET3 activity (Nakamura et al. 2007, 2012). In the paternal pronucleus, PGC7 binds to $\mathrm{H} 3 \mathrm{~K} 9 \mathrm{me} 2$-enriched regions that were not subjected to protamine displacement during spermatogenesis; PGC7 is thus a candidate to protect such histone-specified regions from demethylation (Nakamura et al. 2012).

Protection against demethylation can also be mediated by the ATRX/DAXX/H3.3 and ZFP57/TRIM28 complexes. For the former, we refer to the recent review by Voon \& Gibbons (2016); the focus here will be on a description of the latter. Most DNMT1 is excluded from the paternal pronucleus in accordance with the ongoing global demethylation process (Howell et al. 2001, Hirasawa et al. 2008). However, a minor fraction of DNMT1 is retained in the paternal pronucleus for maintaining methylation in paternal imprinting DMRs through its inclusion in a large protein complex with (1) ZFP57/TRIM28, (2) the nucleosome remodeling and histone deacetylation (NuRD) complex, (3) the H3K9me3 methyltransferase SETDB1, (4) HP1 family proteins, (5) UHRF1 and (6) DNMT3A and DNMT3B (Schultz et al. 2001, Quenneville et al. 2011, Zuo et al. 2012). ZFP57/ TRIM28 is responsible for the locus-specific targeting of the DNMT1 activity to imprinting DMRs by recognizing the consensus sequence TGCCGC in the presence of CpG methylation of the sequence (Quenneville et al. 2011, Liu et al. 2012, Strogantsev et al. 2015). Thus, imprinting DMRs in the paternal pronucleus are protected from 
demethylation through the methylation-dependent recruitment of a methylation-maintaining protein complex; even partial demethylations are rescued to a full methylation phenotype at the imprinting DMR if the ZFP57 recognition site retains some methylation (Tomizawa et al. 2011, Kobayashi et al. 2012). Moreover, the site-specific genomic recruitment of DNMT activity through ZFP57/TRIM28 is tightly associated with the existence of H3K9me3 in imprinted genomic regions (Messerschmidt et al. 2012).

Decreased TRIM28 expression in mice during development is linked to an increased risk of obtaining an obese phenotype in later life, and indications exist that this is also replicated in humans (Dalgaard et al. 2016). Whether this observation is associated with the TRIM28 function in protecting escapees and imprinting DMR against demethylation at preimplantation and/or escapees in PGCs is an intriguing question for future research to address. The resemblance of the demethylation protective DNMT-TRIM28 protein complexes in the preimplantation and PGC stages is also noteworthy. Although the exact mechanisms of protection against demethylation (e.g. the involvement of PGC7 or KRAB-ZFPs such as ZFP57 in complexes with TRIM28, DNMT and other proteins) remain unsolved, this protection could pave the way for epigenetic inheritance through acquired changes in DNA methylation patterns in male gametes, which are not erased during preimplantation (Lane et al. 2003, Smallwood et al. 2011, Kobayashi et al. 2012, Smith et al. 2012, 2014).

\section{Epigenetic inheritance of metabolic diseases through the male germ line}

The interest in epigenetic inheritance of metabolic diseases through the male germ line has rapidly increased in recent years. To date, most experimental studies addressing the mechanistic and descriptive points of epigenetic inheritance have been performed using animal models. While most human studies have been epidemiologically based, a growing number of human studies now include descriptive characterizations of the DNA methylation patterns associated with the inheritance of metabolic diseases. Since reprogramming during gametogenesis and embryogenesis (as described in the former section) is not complete, there is, in principle, room for epigenetic inheritance mediated by DNA methylation in genomic regions with escapee potential. Escapees of preimplantation demethylation might account for the observations of intergenerational epigenetic inheritance. However, for transgenerational epigenetic inheritance through the male germ line to occur, escapees from remodeling during demethylation in PGCs must also exist. To distinguish between inter- and transgenerational effects of DNA methylation escapees, it is important to determine the following: (1) the exact loci for escapees, (2) the functional consequences of such escapees to the transcriptional regulation of the associated genes, and (3) the functional association of an escapee allele with a given phenotype. Notably, numerous single-copy loci escapees have now been identified, including escapees located within genes with functions related to the central nervous system (CNS) and metabolism (Guibert et al. 2012, Seisenberger et al. 2012, Tang et al. 2015). One example is an escapee located in the Exoc4 gene associated with type 2 diabetes and with involvement of the corresponding protein for insulinstimulated glucose transport (Seisenberger et al. 2012). For a comprehensive description of the genomic localization of escapees we refer to the original datasets (Guibert et al. 2012, Seisenberger et al. 2012, Tang et al. 2015). From an evolutionary point of view, heritable epigenetic changes (in the form of epialleles, which are defined as genomic regions with different epigenetic profiles within a population (Finer et al. 2011)) can be beneficial for the efficient development of offspring under given environmental conditions, but at the same time, represent risk-epialleles with the potential to transmit undesirable traits like neurological and metabolic diseases (Pembrey et al. 2014, Tang et al. 2015, Donkin et al. 2016). The best-documented example of epigenetic inheritance by transmittable epialleles is escapees of the IAP element type. Axin 1-fused (Axin1 ${ }^{\mathrm{fu}}$ ) and agouti-viable yellow (Avy) mice are the consequences of IAP element insertion in the context of $A$ or Axin 1 genes, respectively (Duhl et al. 1994, Vasicek et al. 1997). The methylation status of these IAP elements can be modulated by given environmental exposures, with the methylation status reflected in the corresponding transcriptional activity of the $A$ or Axin 1 genes and accordingly manifested mice phenotypes (Cooney et al. 2002, Waterland et al. 2006). Since the $A$ and Axin1 IAP elements possess escapee potential, an environmental exposure-induced DNA methylation alteration can be tracked at both the molecular and phenotypic level through several generations; thus, this represents proof-of-principle for the existence of transgenerational epigenetic inheritance.

\section{DNA methylation-based inheritance through the male germ line of metabolic diseases: lessons from rodent studies}

Several studies have been performed on rodents to investigate how consequences of paternal dietary 
metabolic paradigms can be inherited by offspring. The capability of paternal over-nutrition (with the resulting impaired glucose tolerance and increased body weight) to increase the risk of metabolic disease in offspring is well documented. In a study by Ng and coworkers, three-weekold male rats (F0) were fed a HFD for ten weeks (Ng et al. 2010). Analyses of the F1 offspring showed that female offspring from HFD fathers were at increased risk of lower birth weight, increased blood glucose and reduced insulin secretion. The paternal HFD exposure also reduced islet and beta cell abundances in the F1 offspring, showing the intergenerational transmission of impaired glucoseinsulin homeostasis (Ng et al. 2010).

In an elegant study in mice, Huypens and coworkers examined the relationship between a parental HFD and an offspring's increased susceptibility to develop obesity and diabetes (Huypens et al. 2016). Sperm and oocytes were isolated from F0 mice following a HFD exposure and, after in vitro fertilization, transferred into healthy foster mothers to establish F1 offspring (Huypens et al. 2016). The results showed that female offspring from obese parents gained significantly more weight than offspring from normal weight parents. The outcome was similar if obesity was present for the mother, father or both (Huypens et al. 2016). In addition, offspring from obese fathers showed more cases of extreme obesity compared to offspring from obese mothers. A test for insulin resistance in return showed that HFD-induced insulin resistance was more prominently inherited maternally than paternally (Huypens et al. 2016). Even though this study did not address the molecular epigenetic background of the transmitted phenotype per se, the experimental approach using in vitro fertilization and healthy foster mothers proved that spermatozoa must be able to carry phenotype preprogramming.

In their study, Masuyama and coworkers showed that a paternal HFD before conception resulted in F1 and F2 generations displaying a metabolic phenotype that included weight and fat gain, hypertension, hypertriglyceridemia and glucose intolerance (Masuyama et al. 2016). Moreover, expression of the adipocytokines, adiponectin and leptin was changed in the F1 and F2 offspring, as was the occurrence of the epigenetic chromatin marks H3K9ac and H4K20me1 in the promoter regions of these genes (Masuyama et al. 2016).

Dunn and coworkers addressed the consequences of a maternal HFD during pregnancy in mice offspring and showed increased body size and reduced insulin sensitivity to be present in the F1 and F2 generations; this outcome was transmitted through both the maternal and paternal lineages. In F3, increased body size was only detected in affected females, and this effect only passed through the paternal lineage. This result supports the existence of underlying intergenerational and transgenerational inheritance involving the male germ line (Dunn \& Bale 2011). Even though DNA methylation was not formally analyzed, it was shown that in the F3 generation, the paternal phenotype transmission was specifically associated with alterations in imprinted gene expression, indicating erroneous reprogramming of imprinted loci to be involved in the phenotype transmission (Dunn \& Bale 2011).

Several studies have substantiated the existence of HFD-induced DNA methylation changes in mice sperm and have suggested these changes may be direct participators in phenotype inheritance. Fullston and coworkers showed that a paternal preconception HFD resulted in obesity and insulin resistance in F1 and F2 mice, with incomplete penetrance in the latter generation (Fullston et al. 2013). Interestingly, the study also showed that global DNA methylation and miRNA expression profiles were affected in F0 sperm (Fullston et al. 2013). De Castro Barbosa and coworkers attributed the reduced birth weight in rat offspring in F1, as well as in F2 from F1 males, to be the consequence of a paternal preconception HFD in the F0 generation (de Castro Barbosa et al. 2016). This outcome is in accordance with transgenerational epigenetic inheritance (de Castro Barbosa et al. 2016). Additionally, the pancreatic beta-cell mass was decreased in F1 females. Standard diet (STD)-fed F1 and F2 females from HFD F0 fathers were less glucose tolerant compared to offspring from STD-fed F0 fathers (de Castro Barbosa et al. 2016). If $\mathrm{F} 1$ and $\mathrm{F} 2$ females of HFD F0 fathers were challenged with a HFD for 12 weeks, they were resistant to weight gain, and F2 females displayed further impairments in glucose tolerance (de Castro Barbosa et al. 2016). These effects were mostly absent in male F1 and F2 offspring. Spermatozoa were collected from F0 and F1 males in order to analyze them for DNA methylation changes due to diet (de Castro Barbosa et al. 2016). Numerous DMRs were identified in the spermatozoa from F0-HFD mice and their F1 offspring compared to their respective controls. Eighteen of these DMRs were found in both the F0-HFD mice and their F1 offspring, which could represent potential DNA methylation marks associated with phenotype transmission (de Castro Barbosa et al. 2016). The expression of small ncRNAs was also found to differ between HFD-exposed mice and their controls (de Castro Barbosa et al. 2016).

Changes in the DNA methylation patterns in mice spermatozoa and their corresponding offspring were 
likewise discovered by Wei and coworkers (Wei et al.2014). Paternal prediabetes was induced in the FO generation by a HFD together with low-dose streptozotocin (STZ) specifically displaying cytotoxicity towards pancreatic islet $\beta$-cells (Wei et al. 2014). The results showed that a metabolic phenotype of decreased insulin sensitivity and glucose tolerance was transmitted to the F1 and F2 offspring through the paternal line due to the prediabetes. The induced metabolic phenotype in the F1 and F2 offspring was associated with changes in the expression of genes with important pancreatic islet $\beta$-cell functions as well as changes in the DNA methylation patterns of such genes, as revealed by methylated DNA immunoprecipitation sequencing (MeDIP-seq) and bisulfite sequencing (Wei et al. 2014). Examination of the DNA methylation in the F0 sperm showed the existence of a large amount of dietinduced DMRs and that the sperm epigenome was largely responsive to a prediabetic status. The sperm DMRs were for a subset significantly similar to the DMRs identified in the pancreatic islets of the F1 and F2 offspring, indicating escapees from preimplantation reprogramming and the existence of transgenerational inheritance of DNA methylation changes associated with paternal prediabetes (Wei et al. 2014).

The consequences of restricted nutrition and undernutrition to the risk of transmission of a phenotype have also been carefully examined in mice models. McPherson and coworkers identified that male undernutrition from the age of five weeks resulted in spermatozoa with decreased global methylation and resulted in offspring with reduced postnatal weight and growth and displaying dyslipidemia and fat accumulation (McPherson et al. 2016).

Carone and coworkers showed that male mice fed a low-protein diet (LPD) from weaning onward had offspring with increased liver expression of genes involved in lipid and cholesterol biosynthesis compared to males fed a STD (Carone et al. 2010). The paternal diet influenced the offspring's liver miRNA profile and DNA methylation profile. Reduced representation bisulfite sequencing showed that a paternal LPD resulted in widespread but modest (10-20\%) DNA methylation changes in the liver of offspring (Carone et al. 2010). Significantly, an approximately $30 \%$ increase in methylation was observed for a CGI in a potential enhancer of the gene encoding an important lipid transcription factor (Ppara), and the CGI methylation status inversely correlated to Ppara gene expression (Carone et al. 2010). The paternal diet-induced change in the offspring's Ppara CGI DNA methylation could not be recapitulated for the Ppara CGI in sperm from the F0 fathers. MeDIP-seq analyses also did not identify substantial genome-wide changes in DNA methylation in sperm cells depending on diet. While this result cannot prove the principle that DNA methylation differences in sperm cells are the relevant carriers of epigenetic information, the study supports the importance of epigenetic mechanisms for the transmission of tissuespecific alterations in gene expression in offspring from the paternal diet (Carone et al. 2010).

A follow-up to this study that included more samples and additional novel extensive reduced representation bisulfite sequencing (RRBS) and bisulfite pyrosequencing experiments also failed to identify any major DNA methylation changes in the sperm (Shea et al. 2015). It is notable that male mice fed a HFD were also included in the follow-up study, and the results showed that neither a HFD nor a LPD had a major direct impact on the sperm DNA methylome under the experimentally given dietary conditions (Shea et al. 2015). Another interesting finding from the study was the identification of large diversity in mice sperm DNA methylation patterns for tandem repeat regions and CGI shores between individuals. This methylation variation (due to genetics and unknown environmental effects) was much larger between non-littermates given the same diet than between littermates on different diet paradigms (Shea et al. 2015).

The effect of a maternal LPD on F1 sperm methylation was observed by Holland and coworkers. F0 females were given a LPD until F1 offspring were weaned (Holland et al. 2016). This dietary paradigm resulted in restricted growth in F1 mice, and RRBS analyses of the sperm methylome revealed the existence of a maternal LPD-induced DMR corresponding to repetitive ribosomal RNA-encoding genes (rDNA). Methylation of an rDNA promoter $\mathrm{CpG}$ site at position -133 relative to the transcriptional start site resulted in transcriptional silencing of the underlying rDNA copy and maternal LPD-defined low weaning weight in F1 was negatively correlated with hypomethylation of this site. Additionally, this outcome was specifically dependent on the presence of the A-allele from a neighboring C/A SNP at position -104 (Holland et al. 2016). The study represents an example of an epiallele with transcriptional activity and resulting phenotypic consequences dependent on both early life exposure and genetics (Holland et al. 2016). This result also highlights the important notion that epigenetics, including DNA methylation, not only reflects environmental interactions but, to a large extent, also depends on a particular genetic background (Pembrey et al. 2014). 
The timing of the paternal dietary conditions for the manifestation of DNA methylation changes in sperm has also been elegantly demonstrated by a study in mice from Radford and coworkers (2014). In utero undernourishment during pregnancy resulted in F1 males with low birth weight, early-life adiposity, reduced muscle stem cell number and function, impaired pancreatic function and progressive glucose intolerance. Glucose intolerance and reduced birth weight were inherited by the F2 generation through the paternal line despite the lack of postnatal environmental perturbation of the F1 males (Radford et al. 2014). The timing of the prenatal exposure of the F1 males coincided with the reprogramming of DNA methylation in PGCs (windows of susceptibility 1 and 2, Fig. 3). MeDIP analyses of the F1 sperm identified hypomethylated DMRs from undernourishment relative to the control sperm. Such hypomethylated DMRs are depleted from coding regions but enriched in intergenic regions and CGIs (Radford et al. 2014). Interestingly, these hypomethylated DMRs represent genomic regions with a distinct temporal pattern of DNA methylation reprogramming, namely significantly lower DNA methylation levels at E16.5 than generally observed. This observation indicates that the identified DMRs were late at regaining methylation; accordingly, they could be mechanistically linked to higher susceptibility to environmental perturbations (Radford et al. 2014). Moreover, although the sperm methylome displayed hypermethylation at the end of spermatogenesis, identified undernourishment DMRs were enriched in the genomics regions maintaining hypomethylation despite the general sperm hypermethylation. Finally, $43 \%$ of the undernourishment DMRs were mapping to regions resistant to preimplantation demethylation reprogramming, supporting the assertion that such environmentally induced DMRs persist into at least the early embryo (Radford et al. 2014). Notably, the DMRs were found to be erased in analyses of E16.5 brains and livers from F2 mice. At the same time, however, metabolic pathway genes located in the genomic regions harboring the identified DMRs displayed expression differences in these F2 E16.5 somatic tissues as a consequence of an exposed vs non-exposed F1 generation. Hence, this information indicates the transmittable nature of the metabolic phenotype via predefined gene expression from DNA methylation DMRs present, but later erased, in early development (Radford et al. 2014).

The collective results of these animal studies provide insight into possible mechanisms by which the environmental exposures of fathers can program specific features of the DNA methylome in spermatozoa and how these mechanisms are a risk factor that may affect the metabolic phenotype of the offspring through several generations.

\section{DNA methylation-based inheritance through the male germ line of metabolic diseases: lessons from humans}

A classical study in humans demonstrating the effects of paternal diet on offspring metabolism was performed by Pembrey and coworkers (2006). Epidemiological analyses of the Swedish 'Overkalix' cohort described how the risk of developing cardiovascular disease and diabetes for a man was connected to the grandfather's adequate food intake and the timing of this risk to prepuberty (1013 years) and early adulthood (18-20 years) (Pembrey et al. 2006, Rando 2016). One of the first well-documented molecular descriptions of epigenetic inheritance of a paternal exposure in humans was Soubry and coworkers' study, which analyzed the association between paternal preconception obesity and offspring DNA methylation profiles (Soubry et al. 2013). DNA from the umbilical cord blood of 79 newborns whose parental phenotype characteristics were known was examined through questionnaires and medical records. DNA methylation patterns were analyzed at the imprinted insulin-like growth factor 2 (IGF2) DMR. The results showed a significant association between hypomethylation of the IGF2 gene and paternal obesity. Hypomethylation of IGF2 can lead to increased levels of circulating IGF2, which in previous studies has been associated with high birth weight and an increased risk of obesity and cancer in adulthood (Hoyo et al. 2012). Later, the same group made a similar study on DNA extracted from the umbilical cord blood of 92 newborns and found that paternal obesity was significantly associated with lower methylation levels at multiple imprinted genes important for normal growth and development (Soubry et al. 2015). Despite small sample sizes, both studies suggest that paternal obesity has a preconception influence to reprogram imprinting marks.

Donkin and coworkers studied epigenetic patterns in spermatozoa from lean and obese men (Donkin et al. 2016). They found that obese men had an altered expression of small ncRNAs in their spermatozoa compared to lean men. They also discovered altered DNA methylation patterns relative to the genes controlling CNS function and metabolism, indicating that these genes are potential hotspots for epigenetic variability 
in gametes. An interesting question is whether these regions correlate with the genomic regions discovered by Tang and coworkers for escapees in the human genome (Tang et al. 2015). The Donkin and coworkers study also examined DNA methylation patterns in the spermatozoa of obese men before and after bariatric surgery-mediated weight loss (Donkin et al. 2016). The study showed that the DNA methylation patterns were remodeled rapidly after the surgery, indicating that epigenetic changes can occur during the last stages of sperm maturation. In addition, there was an overlap between the altered genes found between pre- and post-surgery obese men and between lean and obese men, respectively; this result suggests the presence of hotspots for methylation changes in sperm associated with changes in nutritional intake. These studies conducted on humans indicate possible epigenetic inheritance of paternal obesity and a relation between epigenetic variation in gametes and nutritional status. To what extent the described DNA methylation changes influence the future health status of offspring by escaping remodeling in the preimplantation period as well as in future generations by escaping remodeling in PGC remodeling is yet to be determined (Soubry et al. 2015, Donkin et al. 2016).

\section{Perspectives}

For an environmentally induced change in the paternal epigenome to be inherited, it needs to remain stable across the epigenetic reprogramming windows. Since recent studies have shown that this is possible for some epigenetic alterations, the foundation for intergenerational and transgenerational epigenetic inheritance through the male germ line exists (Soubry et al. 2014, Ly et al. 2015). Studies have shown that the inheritable epigenetic marks are primarily associated with genes involved in CNS and metabolism, opening the possibility of the epigenetic inheritance of metabolic disturbances (Tang et al. 2015, Donkin et al. 2016). Animal studies have provided evidence of such epigenetic inheritance by showing altered metabolism in one or more offspring generations after paternal exposure to different nutritional paradigms (Ng et al. 2010, Wei et al. 2014, de Castro Barbosa et al. 2016, Huypens et al. 2016). Animal studies have also provided insight into the mechanisms of how nutritional exposure can affect epigenetic patterns in gametes and somatic tissue.

Although few human studies have been conducted on this subject, existing studies support the possibility of epigenetic inheritance through the human paternal germ line. The human studies have shown that epigenetic changes in spermatozoa can occur rapidly and in response to different nutritional statuses or other lifestyle conditions (Hoyo et al. 2012, Soubry et al. 2013, 2015). These studies have not yet provided an in-depth understanding of the specific mechanisms behind epigenetic inheritance or exact effect size for the disease risk in offspring. Although rodents provide convenient models for human diseases and behavioral traits, they differ notably from humans in physiological and biological processes (Nagy \& Turecki 2015, Stegemann \& Buchner 2015). Nevertheless, the studies presented here support the notion that environmentally induced DNA methylation changes in the father can be transmitted to offspring and operate as a risk factor for metabolic diseases in later life and eventually across several generations. Hence, these findings may help explain the high prevalence of obesity, type 2 diabetes, and other metabolic diseases. These findings also provide an interesting possibility for the future treatment and diagnostics of metabolic diseases based on the knowledge of epigenetics, including DNA methylation. Moreover, further identification of epigenetic markers in gametes and offspring as well as detection of sensitive windows of exposure may help more accurately predict an offspring's susceptibility to a disease (Wei et al. 2015).

Whether DNA methylation changes associated with trans- and intergenerational inheritance of epigenetically based phenotypes are phenotype driver or passenger events is a highly relevant question. Evidence could argue that DNA methylation alone is less likely to be the primary mechanism for epigenetic inheritance through sperm, given that it seems increasingly well established that chromatin modifications and ncRNA (i.e., miRNAs and tRNA-derived fragments) are also key mediators in epigenetic inheritance (Fullston et al. 2013, Chen et al. 2016, Sharma et al. 2016). The existence of DNA methylation changes in sperm related to defined paternal dietary exposures within windows of susceptibility 1 and 2 seems evident. However, the existence of DNA methylation changes in sperm related to dietary exposures in later stages of spermatogenesis can still be debated (Shea et al. 2015). The presence of dietary-induced DNA methylation changes may arise from specific cellular signal transduction affecting the male germ cells during gametogenesis in response to a given environmental context. More indirect mechanisms are also plausible, such as the obesity phenotype in males being associated with increased testicular temperature due to fat accumulation and increased concentrations of serum biomarkers such as insulin and glucose. These factors could all potentially 
affect the DNA methylation reprogramming in male gametes (Du Plessis et al. 2010, Wei et al. 2014).

The fact that the literature has only reported modest methylation changes (less than 20\%) at given genomic positions in sperm cell populations of cases and controls is also important to emphasize. Since the sperm genome is haploid, the methylation status must be either 0 or $100 \%$ at each CpG site. Thus, a change of less than $20 \%$ indicates that fewer than 1 in 5 sperm cells harbor an altered methylation status at the given position and hereby the ability to transmit this change to the following generations (Shea et al. 2015). This observation counteracts the often described very high effect size of paternal phenotype transmission to offspring. A mechanistic explanation for this discrepancy could be that CpG sites in a cluster adapt to all having the same methylation status (Shea et al. 2015). Thus, in a population of sperm cells, aberrant methylation at different single $\mathrm{CpG}$ sites within a given cluster could predefine an identical aberrant methylation status for the entire CpG site cluster in the offspring. In such a model, functional important CpG site methylation aberrations will not necessarily appear at identical genomic positions in methylation analyses of sperm cell populations or at the single sperm cell level, but instead appear with an increased stochastic variation over given genomic regions (Shea et al. 2015).

The precise mechanistic deciphering of epiallele inheritance through the male germ line and how specific CpG site methylation events can specify offspring phenotypes has been hampered by the lack of an experimental molecular toolbox to study specific genome-edited CpG site methylation. Pharmacological approaches have reached their limits in the concurrent targeting of many genomic regions simultaneously with DNMT and TET antagonists and agonists. However, the recent implementation of modified clustered regularly interspaced short palindromic repeat CRISPR associated protein (CRISPR-Cas9) genomic engineering tools have provided new possibilities for site-specific remodeling of the epigenome (Doudna \& Charpentier 2014). The catalytically inactive Cas9 protein (dCas9) can be fused to transcriptional regulatory domains such as KRAB for silencing and VP64 for activation. If introduced in a cellular context together with single guide RNA (sgRNA), this system can be used to direct transcriptional repression or activation to specific loci through the specificity of the sgRNA sequence (Konermann et al. 2015, Shalem et al. 2015, O'Geen et al. 2017). The CRISPR-Cas9 system has also been modified to direct single loci-specific de novo DNA methylation by fusing dCas9 with DNMT3A (Liu et al. 2016, McDonald et al. 2016, Stepper et al. 2016, Vojta et al. 2016, O'Geen et al. 2017) or DNA demethylation by fusing dCas9 with TET1 (Choudhury et al. 2016, Liu et al. 2016). Despite the continuing lack of an exhaustive clarification of eventual off-target effects, CRISPR-dCas9 systems could allow a future functional description of the importance of the methylation status of individual or clusters of $\mathrm{CpG}$ sites for epigenetic inheritance of metabolic diseases.

\section{Concluding remarks}

Future studies are necessary to confirm the association between paternal exposures, inter- and transgenerational epigenetic inheritance, and the susceptibility of offspring to metabolic diseases. Deciphering the mechanisms controlling epigenetic inheritance in humans could raise societal awareness of behavior to prevent a further rise in the prevalence of metabolic diseases in future generations.

Declaration of interest

The authors declare that there is no conflict of interest that could be perceived as prejudicing the impartiality of this review.

Funding

S T B was supported by a fellowship from Health, Aarhus University.

\section{Acknowledgements}

The authors thank the Lundbeck Foundation for making this study possible.

\section{References}

Anway MD, Cupp AS, Uzumcu M \& Skinner MK 2005 Epigenetic transgenerational actions of endocrine disruptors and male fertility. Science 308 1466-1469. (https://doi.org/10.1126/science.1108190)

Arand J, Spieler D, Karius T, Branco MR, Meilinger D, Meissner A, Jenuwein T, Xu G, Leonhardt H, Wolf V, et al. 2012 In vivo control of CpG and non-CpG DNA methylation by DNA methyltransferases. PLoS Genetics 8 e1002750. (https://doi.org/10.1371/journal. pgen.1002750)

Arand J, Wossidlo M, Lepikhov K, Peat JR, Reik W \& Walter J 2015 Selective impairment of methylation maintenance is the major cause of DNA methylation reprogramming in the early embryo. Epigenetics and Chromatin 8 1. (https://doi.org/10.1186/1756-8935-8-1)

Ball MP, Li JB, Gao Y, Lee JH, LeProust EM, Park IH, Xie B, Daley GQ \& Church GM 2009 Targeted and genome-scale strategies reveal genebody methylation signatures in human cells. Nature Biotechnology $\mathbf{2 7}$ 361-368. (https://doi.org/10.1038/nbt.1533)

Barres R, Osler ME, Yan J, Rune A, Fritz T, Caidahl K, Krook A \& Zierath JR 2009 Non-CpG methylation of the PGC-1alpha promoter through DNMT3B controls mitochondrial density. Cell Metabolism 10 189-198. (https://doi.org/10.1016/j.cmet.2009.07.011) 
Baubec T, Colombo DF, Wirbelauer C, Schmidt J, Burger L, Krebs AR, Akalin A \& Schubeler D 2015 Genomic profiling of DNA methyltransferases reveals a role for DNMT3B in genic methylation. Nature 520 243-247. (https://doi.org/10.1038/nature14176)

Bian C \& Yu X 2014 PGC7 suppresses TET3 for protecting DNA methylation. Nucleic Acids Research 42 2893-2905. (https://doi. org/10.1093/nar/gkt1261)

Bibikova M, Barnes B, Tsan C, Ho V, Klotzle B, Le JM, Delano D, Zhang L, Schroth GP, Gunderson KL, et al. 2011 High density DNA methylation array with single CpG site resolution. Genomics 98 288-295. (https://doi.org/10.1016/j.ygeno.2011.07.007)

Biniszkiewicz D, Gribnau J, Ramsahoye B, Gaudet F, Eggan K, Humpherys D, Mastrangelo MA, Jun Z, Walter J \& Jaenisch R 2002 Dnmt1 overexpression causes genomic hypermethylation, loss of imprinting, and embryonic lethality. Molecular and Cellular Biology 22 2124-2135. (https://doi.org/10.1128/MCB.22.7.2124-2135.2002)

Bird A 2002 DNA methylation patterns and epigenetic memory. Genes and Development 16 6-21. (https://doi.org/10.1101/gad.947102)

Branco MR, Oda M \& Reik W 2008 Safeguarding parental identity: Dnmt1 maintains imprints during epigenetic reprogramming in early embryogenesis. Genes and Development 22 1567-1571. (https:// doi.org/10.1101/gad.1690508)

Brown SJ, Stoilov P \& Xing Y 2012 Chromatin and epigenetic regulation of pre-mRNA processing. Human Molecular Genetics 21 R90-R96. (https://doi.org/10.1093/hmg/dds353)

Brykczynska U, Hisano M, Erkek S, Ramos L, Oakeley EJ, Roloff TC, Beisel C, Schubeler D, Stadler MB \& Peters AH 2010 Repressive and active histone methylation mark distinct promoters in human and mouse spermatozoa. Nature Structural and Molecular Biology 17 679-687. (https://doi.org/10.1038/nsmb.1821)

Canovas S \& Ross PJ 2016 Epigenetics in preimplantation mammalian development. Theriogenology 86 69-79. (https://doi.org/10.1016/j. theriogenology.2016.04.020)

Carone BR, Fauquier L, Habib N, Shea JM, Hart CE, Li R, Bock C, Li C, Gu H, Zamore PD, et al. 2010 Paternally induced transgenerational environmental reprogramming of metabolic gene expression in mammals. Cell 143 1084-1096. (https://doi.org/10.1016/j. cell.2010.12.008)

Chen Q, Yan M, Cao Z, Li X, Zhang Y, Shi J, Feng GH, Peng H, Zhang X, Zhang Y, et al. 2016 Sperm tsRNAs contribute to intergenerational inheritance of an acquired metabolic disorder. Science 351 397-400. (https://doi.org/10.1126/science.aad7977)

Choudhury SR, Cui Y, Lubecka K, Stefanska B \& Irudayaraj J 2016 CRISPR-dCas 9 mediated TET1 targeting for selective DNA demethylation at BRCA1 promoter. Oncotarget 7 46545-46556. (https://doi.org/10.18632/oncotarget.10234)

Cirio MC, Ratnam S, Ding F, Reinhart B, Navara C \& Chaillet JR 2008 Preimplantation expression of the somatic form of Dnmt1 suggests a role in the inheritance of genomic imprints. BMC Developmental Biology 8 9. (https://doi.org/10.1186/1471-213X-8-9)

Cooney CA, Dave AA \& Wolff GL 2002 Maternal methyl supplements in mice affect epigenetic variation and DNA methylation of offspring. Journal of Nutrition 132 (Supplement 8) 2393S-2400S.

Court F, Tayama C, Romanelli V, Martin-Trujillo A, Iglesias-Platas I, Okamura K, Sugahara N, Simon C, Moore H, Harness JV, et al. 2014 Genome-wide parent-of-origin DNA methylation analysis reveals the intricacies of human imprinting and suggests a germline methylation-independent mechanism of establishment. Genome Research 24 554-569. (https://doi.org/10.1101/gr.164913.113)

Curley JP, Mashoodh R \& Champagne FA 2011 Epigenetics and the origins of paternal effects. Hormones and Behavior 59 306-314. (https://doi.org/10.1016/j.yhbeh.2010.06.018)

Dalgaard K, Landgraf K, Heyne S, Lempradl A, Longinotto J, Gossens K, Ruf M, Orthofer M, Strogantsev R, Selvaraj M, et al. 2016 Trim28 haploinsufficiency triggers bi-stable epigenetic obesity. Cell 164 353-364. (https://doi.org/10.1016/j.cell.2015.12.025)
Dawlaty MM, Breiling A, Le T, Raddatz G, Barrasa MI, Cheng AW, Gao Q, Powell BE, Li Z, Xu M, et al. 2013 Combined deficiency of Tet 1 and Tet 2 causes epigenetic abnormalities but is compatible with postnatal development. Developmental Cell 24 310-323. (https://doi. org/10.1016/j.devcel.2012.12.015)

de Castro Barbosa T, Ingerslev LR, Alm PS, Versteyhe S, Massart J, Rasmussen M, Donkin I, Sjogren R, Mudry JM, Vetterli L, et al. 2016 High-fat diet reprograms the epigenome of rat spermatozoa and transgenerationally affects metabolism of the offspring. Molecular Metabolism 5 184-197. (https://doi.org/10.1016/j. molmet.2015.12.002)

Deaton AM \& Bird A 2011 CpG islands and the regulation of transcription. Genes and Development 25 1010-1022. (https://doi. org/10.1101/gad.2037511)

Doi A, Park IH, Wen B, Murakami P, Aryee MJ, Irizarry R, Herb B, LaddAcosta C, Rho J, Loewer S, et al. 2009 Differential methylation of tissue- and cancer-specific CpG island shores distinguishes human induced pluripotent stem cells embryonic stem cells and fibroblasts. Nature Genetics 41 1350-1353. (https://doi.org/10.1038/ng.471)

Donkin I, Versteyhe S, Ingerslev LR, Qian K, Mechta M, Nordkap L, Mortensen B, Appel EV, Jorgensen N, Kristiansen VB, et al. 2016 Obesity and bariatric surgery drive epigenetic variation of spermatozoa in humans. Cell Metabolism 23 369-378. (https://doi. org/10.1016/j.cmet.2015.11.004)

Doudna JA \& Charpentier E 2014 Genome editing. The new frontier of genome engineering with CRISPR-Cas9. Science 3461258096. (https://doi.org/10.1126/science.1258096)

Du Plessis SS, Cabler S, McAlister DA, Sabanegh E \& Agarwal A 2010 The effect of obesity on sperm disorders and male infertility. Nature Reviews Urology 7 153-161. (https://doi.org/10.1038/nrurol.2010.6)

Duhl DM, Vrieling H, Miller KA, Wolff GL \& Barsh GS 1994 Neomorphic agouti mutations in obese yellow mice. Nature Genetics 8 59-65. (https://doi.org/10.1038/ng0994-59)

Dunn GA \& Bale TL 2011 Maternal high-fat diet effects on thirdgeneration female body size via the paternal lineage. Endocrinology 152 2228-2236. (https://doi.org/10.1210/en.2010-1461)

Edgar R, Tan PP, Portales-Casamar E \& Pavlidis P 2014 Meta-analysis of human methylomes reveals stably methylated sequences surrounding CpG islands associated with high gene expression. Epigenetics and Chromatin 7 28. (https://doi.org/10.1186/1756-8935-7-28)

Finer S, Holland ML, Nanty L \& Rakyan VK 2011 The hunt for the epiallele. Environmental and Molecular Mutagenesis 52 1-11. (https:// doi.org/10.1002/em.20590)

Fullston T, Ohlsson Teague EM, Palmer NO, DeBlasio MJ, Mitchell M, Corbett M, Print CG, Owens JA \& Lane M 2013 Paternal obesity initiates metabolic disturbances in two generations of mice with incomplete penetrance to the F2 generation and alters the transcriptional profile of testis and sperm microRNA content. FASEB Journal 27 4226-4243. (https://doi.org/10.1096/fj.12-224048)

Gardiner-Garden M \& Frommer M 1987 CpG islands in vertebrate genomes. Journal of Molecular Biology 196 261-282. (https://doi. org/10.1016/0022-2836(87)90689-9)

Gkountela S, Zhang KX, Shafiq TA, Liao WW, Hargan-Calvopina J, Chen PY \& Clark AT 2015 DNA demethylation dynamics in the human prenatal germline. Cell 161 1425-1436. (https://doi. org/10.1016/j.cell.2015.05.012)

Goyal R, Reinhardt R \& Jeltsch A 2006 Accuracy of DNA methylation pattern preservation by the Dnmt1 methyltransferase. Nucleic Acids Research 34 1182-1188. (https://doi.org/10.1093/nar/gkl002)

Grandjean V, Yaman R, Cuzin F \& Rassoulzadegan M 2007 Inheritance of an epigenetic mark: the CpG DNA methyltransferase 1 is required for de novo establishment of a complex pattern of non-CpG methylation. PLOS ONE 2 e1136. (https://doi.org/10.1371/journal. pone.0001136)

Gu TP, Guo F, Yang H, Wu HP, Xu GF, Liu W, Xie ZG, Shi L, He X, Jin SG, et al. 2011 The role of Tet3 DNA dioxygenase in epigenetic 
reprogramming by oocytes. Nature 477 606-610. (https://doi. org/10.1038/nature10443)

Guerrero-Bosagna C, Settles M, Lucker B \& Skinner MK 2010 Epigenetic transgenerational actions of vinclozolin on promoter regions of the sperm epigenome. PLOS ONE 5 e13100. (https://doi.org/10.1371/ journal.pone.0013100)

Guibert S, Forne T \& Weber M 2012 Global profiling of DNA methylation erasure in mouse primordial germ cells. Genome Research 22 633-641. (https://doi.org/10.1101/gr.130997.111)

Guo F, Li X, Liang D, Li T, Zhu P, Guo H, Wu X, Wen L, Gu TP, Hu B, et al. 2014 Active and passive demethylation of male and female pronuclear DNA in the mammalian zygote. Cell Stem Cell $\mathbf{1 5}$ 447-458. (https://doi.org/10.1016/j.stem.2014.08.003)

Guo F, Yan L, Guo H, Li L, Hu B, Zhao Y, Yong J, Hu Y, Wang X, Wei Y, et al. 2015 The transcriptome and DNA methylome landscapes of human primordial germ cells. Cell 161 1437-1452. (https://doi. org/10.1016/j.cell.2015.05.015)

Hackett JA, Sengupta R, Zylicz JJ, Murakami K, Lee C, Down TA \& Surani MA 2013 Germline DNA demethylation dynamics and imprint erasure through 5-hydroxymethylcytosine. Science 339 448-452. (https://doi.org/10.1126/science.1229277)

Hajkova P 2011 Epigenetic reprogramming in the germline: towards the ground state of the epigenome. Philosophical Transactions of the Royal Society of London: Series B, Biological Sciences 366 2266-2273. (https:// doi.org/10.1098/rstb.2011.0042)

Hammoud SS, Nix DA, Zhang H, Purwar J, Carrell DT \& Cairns BR 2009 Distinctive chromatin in human sperm packages genes for embryo development. Nature 460 473-478. (https:doi.org/10.1038/ nature08162)

Hammoud SS, Low DH, Yi C, Carrell DT, Guccione E \& Cairns BR 2014 Chromatin and transcription transitions of mammalian adult germline stem cells and spermatogenesis. Cell Stem Cell 15 239-253. (https://doi.org/10.1016/j.stem.2014.04.006)

Heard E \& Martienssen RA 2014 Transgenerational epigenetic inheritance: myths and mechanisms. Cell 157 95-109. (https://doi. org/10.1016/j.cell.2014.02.045)

Hirasawa R, Chiba H, Kaneda M, Tajima S, Li E, Jaenisch R \& Sasaki H 2008 Maternal and zygotic Dnmt1 are necessary and sufficient for the maintenance of DNA methylation imprints during preimplantation development. Genes and Development 22 1607-1616. (https://doi.org/10.1101/gad.1667008)

Holland ML, Lowe R, Caton PW, Gemma C, Carbajosa G, Danson AF, Carpenter AA, Loche E, Ozanne SE \& Rakyan VK 2016 Early-life nutrition modulates the epigenetic state of specific rDNA genetic variants in mice. Science 353 495-498. (https://doi.org/10.1126/ science.aaf7040)

Howell CY, Bestor TH, Ding F, Latham KE, Mertineit C, Trasler JM \& Chaillet JR 2001 Genomic imprinting disrupted by a maternal effect mutation in the Dnmt1 gene. Cell 104 829-838. (https://doi. org/10.1016/S0092-8674(01)00280-X)

Howlett SK \& Reik W 1991 Methylation levels of maternal and paternal genomes during preimplantation development. Development 113 119-127.

Hoyo C, Fortner K, Murtha AP, Schildkraut JM, Soubry A, DemarkWahnefried W, Jirtle RL, Kurtzberg J, Forman MR, Overcash F, et al. 2012 Association of cord blood methylation fractions at imprinted insulin-like growth factor 2 (IGF2), plasma IGF2, and birth weight. Cancer Causes and Control 23 635-645. (https://doi.org/10.1007/ s10552-012-9932-y)

Huh I, Zeng J, Park T \& Yi SV 2013 DNA methylation and transcriptional noise. Epigenetics and Chromatin 6 9. (https://doi. org/10.1186/1756-8935-6-9)

Huypens P, Sass S, Wu M, Dyckhoff D, Tschop M, Theis F, Marschall S, Hrabe de Angelis M \& Beckers J 2016 Epigenetic germline inheritance of diet-induced obesity and insulin resistance. Nature Genetics 48 497-499. (https://doi.org/10.1038/ng.3527)
Ichiyanagi T, Ichiyanagi K, Miyake M \& Sasaki H 2013 Accumulation and loss of asymmetric non-CpG methylation during male germ-cell development. Nucleic Acids Research 41 738-745. (https://doi. org/10.1093/nar/gks1117)

Inoue A \& Zhang Y 2011 Replication-dependent loss of 5-hydroxymethylcytosine in mouse preimplantation embryos. Science 334 194. (https://doi.org/10.1126/science.1212483)

Ioshikhes IP \& Zhang MQ 2000 Large-scale human promoter mapping using CpG islands. Nature Genetics 26 61-63. (https://doi. org/10.1038/79189)

Iqbal K, Jin SG, Pfeifer GP \& Szabo PE 2011 Reprogramming of the paternal genome upon fertilization involves genome-wide oxidation of 5-methylcytosine. PNAS 108 3642-3647. (https://doi.org/10.1073/ pnas.1014033108)

Irizarry RA, Ladd-Acosta C, Wen B, Wu Z, Montano C, Onyango P, Cui H, Gabo K, Rongione M, Webster M, et al. 2009 The human colon cancer methylome shows similar hypo- and hypermethylation at conserved tissue-specific CpG island shores. Nature Genetics 41 178-186. (https://doi.org/10.1038/ng.298)

Jacobs FM, Greenberg D, Nguyen N, Haeussler M, Ewing AD, Katzman S, Paten B, Salama SR\& Haussler D 2014 An evolutionary arms race between KRAB zinc-finger genes ZNF91/93 and SVA/L1 retrotransposons. Nature 516 242-245. (https://doi.org/10.1038/ nature13760)

Jones PA 2012 Functions of DNA methylation: islands, start sites, gene bodies and beyond. Nature Reviews Genetics 13 484-492. (https://doi. org/10.1038/nrg3230)

Jones PA \& Liang G 2009 Rethinking how DNA methylation patterns are maintained. Nature Reviews Genetics 10 805-811. (https://doi. org/10.1038/nrg2651)

Jurkowska RZ, Jurkowski TP \& Jeltsch A 2011 Structure and function of mammalian DNA methyltransferases. ChemBioChem 12 206-222. (https://doi.org/10.1002/cbic.201000195)

Kagiwada S, Kurimoto K, Hirota T, Yamaji M \& Saitou M 2013 Replication-coupled passive DNA demethylation for the erasure of genome imprints in mice. The EMBO Journal 32 340-353. (https:// doi.org/10.1038/emboj.2012.331)

Kato Y, Kaneda M, Hata K, Kumaki K, Hisano M, Kohara Y, Okano M, Li E, Nozaki M \& Sasaki H 2007 Role of the Dnmt3 family in de novo methylation of imprinted and repetitive sequences during male germ cell development in the mouse. Human Molecular Genetics 16 2272-2280. (https://doi.org/10.1093/hmg/ddm179)

Kobayashi H, Sakurai T, Imai M, Takahashi N, Fukuda A, Yayoi O, Sato S, Nakabayashi K, Hata K, Sotomaru Y, et al. 2012 Contribution of intragenic DNA methylation in mouse gametic DNA methylomes to establish oocyte-specific heritable marks. PLoS Genetics 8 e1002440. (https://doi.org/10.1371/journal.pgen.1002440)

Kobayashi H, Sakurai T, Miura F, Imai M, Mochiduki K, Yanagisawa E, Sakashita A, Wakai T, Suzuki Y, Ito T, et al. 2013 High-resolution DNA methylome analysis of primordial germ cells identifies genderspecific reprogramming in mice. Genome Research 23 616-627. (https://doi.org/10.1101/gr.148023.112)

Kohli RM \& Zhang Y 2013 TET enzymes, TDG and the dynamics of DNA demethylation. Nature 502 472-479. (https://doi.org/10.1038/ nature12750)

Konermann S, Brigham MD, Trevino AE, Joung J, Abudayyeh OO, Barcena C, Hsu PD, Habib N, Gootenberg JS, Nishimasu H, et al. 2015 Genome-scale transcriptional activation by an engineered CRISPR-Cas9 complex. Nature 517 583-588. (https://doi.org/10.1038/ nature14136)

Kurimoto K, Yabuta Y, Ohinata Y, Shigeta M, Yamanaka K \& Saitou M 2008 Complex genome-wide transcription dynamics orchestrated by Blimp1 for the specification of the germ cell lineage in mice. Genes and Development 22 1617-1635. (https://doi.org/10.1101/gad.1649908)

Lane N, Dean W, Erhardt S, Hajkova P, Surani A, Walter J \& Reik W 2003 Resistance of IAPs to methylation reprogramming may provide 
a mechanism for epigenetic inheritance in the mouse. Genesis $\mathbf{3 5}$ 88-93. (https://doi.org/10.1002/gene.10168)

Laurent L, Wong E, Li G, Huynh T, Tsirigos A, Ong CT, Low HM, Kin Sung KW, Rigoutsos I, Loring J, et al. 2010 Dynamic changes in the human methylome during differentiation. Genome Research 20 320-331. (https://doi.org/10.1101/gr.101907.109)

Li E, Bestor TH \& Jaenisch R 1992 Targeted mutation of the DNA methyltransferase gene results in embryonic lethality. Cell 69 915-926. (https://doi.org/10.1016/0092-8674(92)90611-F)

Lister R, Pelizzola M, Dowen RH, Hawkins RD, Hon G, Tonti-Filippini J, Nery JR, Lee L, Ye Z, Ngo QM, et al. 2009 Human DNA methylomes at base resolution show widespread epigenomic differences. Nature 462 315-322. (https://doi.org/10.1038/nature08514)

Liu Y, Toh H, Sasaki H, Zhang X \& Cheng X 2012 An atomic model of Zfp57 recognition of CpG methylation within a specific DNA sequence. Genes and Development 26 2374-2379. (https://doi. org/10.1101/gad.202200.112)

Liu XS, Wu H, Ji X, Stelzer Y, Wu X, Czauderna S, Shu J, Dadon D, Young RA \& Jaenisch R 2016 Editing DNA methylation in the mammalian genome. Cell 167 233.e17-247.e17. (https://doi. org/10.1016/j.cell.2016.08.056)

Ly L, Chan D \& Trasler JM 2015 Developmental windows of susceptibility for epigenetic inheritance through the male germline. Seminars in Cell and Developmental Biology 43 96-105. (https://doi. org/10.1016/j.semcdb.2015.07.006)

Magnusdottir E, Dietmann S, Murakami K, Gunesdogan U, Tang F, Bao S, Diamanti E, Lao K, Gottgens B \& Azim Surani M 2013 A tripartite transcription factor network regulates primordial germ cell specification in mice. Nature Cell Biology 15 905-915. (https://doi. org/10.1038/ncb2798)

Marcho C, Cui W \& Mager J 2015 Epigenetic dynamics during preimplantation development. Reproduction 150 R109-R120. (https:// doi.org/10.1530/REP-15-0180)

Marques CJ, Joao Pinho M, Carvalho F, Bieche I, Barros A \& Sousa M 2011 DNA methylation imprinting marks and DNA methyltransferase expression in human spermatogenic cell stages. Epigenetics 6 1354-1361. (https://doi.org/10.4161/epi.6.11.17993)

Masuyama H, Mitsui T, Eguchi T, Tamada S \& Hiramatsu Y 2016 The effects of paternal high-fat diet exposure on offspring metabolism with epigenetic changes in the mouse adiponectin and leptin gene promoters. American Journal of Physiology: Endocrinology and Metabolism 311 E236-E245. (https://doi.org/10.1152/ajpendo.00095.2016)

Mayer W, Niveleau A, Walter J, Fundele R \& Haaf T 2000 Demethylation of the zygotic paternal genome. Nature $\mathbf{4 0 3}$ 501-502. (https://doi. org/10.1038/35000656)

McDonald JI, Celik H, Rois LE, Fishberger G, Fowler T, Rees R, Kramer A, Martens A, Edwards JR \& Challen GA 2016 Reprogrammable CRISPR/ Cas9-based system for inducing site-specific DNA methylation. Biology Open 5 866-874. (https://doi.org/10.1242/bio.019067)

McPherson NO, Fullston T, Kang WX, Sandeman LY, Corbett MA, Owens JA \& Lane M 2016 Paternal under-nutrition programs metabolic syndrome in offspring which can be reversed by antioxidant/vitamin food fortification in fathers. Scientific Reports 6 27010. (https://doi.org/10.1038/srep27010)

Meissner A, Mikkelsen TS, Gu H, Wernig M, Hanna J, Sivachenko A, Zhang X, Bernstein BE, Nusbaum C, Jaffe DB, et al. 2008 Genomescale DNA methylation maps of pluripotent and differentiated cells. Nature 454 766-770. (https://doi.org/10.1038/nature07107)

Messerschmidt DM, de Vries W, Ito M, Solter D, Ferguson-Smith A \& Knowles BB 2012 Trim28 is required for epigenetic stability during mouse oocyte to embryo transition. Science 335 1499-1502. (https:// doi.org/10.1126/science.1216154)

Messerschmidt DM, Knowles BB \& Solter D 2014 DNA methylation dynamics during epigenetic reprogramming in the germline and preimplantation embryos. Genes and Development 28 812-828. (https://doi.org/10.1101/gad.234294.113)
Miller D, Brinkworth M \& Iles D 2010 Paternal DNA packaging in spermatozoa: more than the sum of its parts? DNA, histones, protamines and epigenetics. Reproduction 139 287-301. (https://doi. org/10.1530/REP-09-0281)

Molaro A, Falciatori I, Hodges E, Aravin AA, Marran K, Rafii S, McCombie WR, Smith AD \& Hannon GJ 2014 Two waves of de novo methylation during mouse germ cell development. Genes and Development 28 1544-1549. (https://doi.org/10.1101/gad.244350.114)

Monk D 2015 Germline-derived DNA methylation and early embryo epigenetic reprogramming: the selected survival of imprints. International Journal of Biochemistry and Cell Biology 67 128-138. (https://doi.org/10.1016/j.biocel.2015.04.014)

Morgan HD, Santos F, Green K, Dean W \& Reik W 2005 Epigenetic reprogramming in mammals. Human Molecular Genetics 14 R47-R58. (https://doi.org/10.1093/hmg/ddi114)

Nagy C \& Turecki G 2015 Transgenerational epigenetic inheritance: an open discussion. Epigenomics 7 781-790. (https://doi.org/10.2217/ epi.15.46)

Nakamura T, Arai Y, Umehara H, Masuhara M, Kimura T, Taniguchi H, Sekimoto T, Ikawa M, Yoneda Y, Okabe M, et al. 2007 PGC7/Stella protects against DNA demethylation in early embryogenesis. Nature Cell Biology 9 64-71. (https://doi.org/10.1038/ncb1519)

Nakamura T, Liu YJ, Nakashima H, Umehara H, Inoue K, Matoba S, Tachibana M, Ogura A, Shinkai Y \& Nakano T 2012 PGC7 binds histone $\mathrm{H} 3 \mathrm{~K} 9 \mathrm{me} 2$ to protect against conversion of $5 \mathrm{mC}$ to $5 \mathrm{hmC}$ in early embryos. Nature $\mathbf{4 8 6}$ 415-419. (https://doi.org/10.1038/ nature11093)

Neri F, Rapelli S, Krepelova A, Incarnato D, Parlato C, Basile G, Maldotti M, Anselmi F \& Oliviero S 2017 Intragenic DNA methylation prevents spurious transcription initiation. Nature $\mathbf{5 4 3}$ 72-77. (https://doi.org/10.1038/nature21373)

Ng SF, Lin RC, Laybutt DR, Barres R, Owens JA \& Morris MJ 2010 Chronic high-fat diet in fathers programs beta-cell dysfunction in female rat offspring. Nature 467 963-966. (https://doi.org/10.1038/ nature09491)

Niles KM, Yeh JR, Chan D, Landry M, Nagano MC \& Trasler JM 2013 Haploinsufficiency of the paternal-effect gene Dnmt3L results in transient DNA hypomethylation in progenitor cells of the male germline. Human Reproduction 28 519-530. (https://doi.org/10.1093/ humrep/des395)

O'Geen H, Ren C, Nicolet CM, Perez AA, Halmai J, Le VM, Mackay JP, Farnham PJ \& Segal DJ 2017 dCas9-based epigenome editing suggests acquisition of histone methylation is not sufficient for target gene repression. Nucleic Acids Research 45 9901-9916.

Oakes CC, La Salle S, Smiraglia DJ, Robaire B \& Trasler JM 2007 Developmental acquisition of genome-wide DNA methylation occurs prior to meiosis in male germ cells. Developmental Biology $\mathbf{3 0 7}$ 368-379. (https://doi.org/10.1016/j.ydbio.2007.05.002)

Ohno R, Nakayama M, Naruse C, Okashita N, Takano O, Tachibana M, Asano M, Saitou M \& Seki Y 2013 A replication-dependent passive mechanism modulates DNA demethylation in mouse primordial germ cells. Development 140 2892-2903. (https://doi.org/10.1242/ dev.093229)

Okano M, Bell DW, Haber DA \& Li E 1999 DNA methyltransferases Dnmt3a and Dnmt3b are essential for de novo methylation and mammalian development. Cell 99 247-257. (https://doi.org/10.1016/ S0092-8674(00)81656-6)

Oswald J, Engemann S, Lane N, Mayer W, Olek A, Fundele R, Dean W, Reik W \& Walter J 2000 Active demethylation of the paternal genome in the mouse zygote. Current Biology: CB 10 475-478. (https://doi.org/10.1016/S0960-9822(00)00448-6)

Peat JR, Dean W, Clark SJ, Krueger F, Smallwood SA, Ficz G, Kim JK, Marioni JC, Hore TA \& Reik W 2014 Genome-wide bisulfite sequencing in zygotes identifies demethylation targets and maps the contribution of TET3 oxidation. Cell Reports 9 1990-2000. (https:// doi.org/10.1016/j.celrep.2014.11.034) 
Pembrey ME, Bygren LO, Kaati G, Edvinsson S, Northstone K, Sjostrom M \& Golding J 2006 Sex-specific, male-line transgenerational responses in humans. European Journal of Human Genetics: EJHG 14 159-166. (https://doi.org/10.1038/sj.ejhg.5201538)

Pembrey M, Saffery R \& Bygren LO 2014 Human transgenerational responses to early-life experience: potential impact on development, health and biomedical research. Journal of Medical Genetics $\mathbf{5 1}$ 563-572. (https://doi.org/10.1136/jmedgenet-2014-102577)

Perera F \& Herbstman J 2011 Prenatal environmental exposures, epigenetics, and disease. Reproductive Toxicology 31 363-373. (https:// doi.org/10.1016/j.reprotox.2010.12.055)

Proudhon C, Duffie R, Ajjan S, Cowley M, Iranzo J, Carbajosa G, Saadeh H, Holland ML, Oakey RJ, Rakyan VK, et al. 2012 Protection against de novo methylation is instrumental in maintaining parentof-origin methylation inherited from the gametes. Molecular Cell $\mathbf{4 7}$ 909-920. (https://doi.org/10.1016/j.molcel.2012.07.010)

Quenneville S, Verde G, Corsinotti A, Kapopoulou A, Jakobsson J, Offner S, Baglivo I, Pedone PV, Grimaldi G, Riccio A, et al. 2011 In embryonic stem cells, ZFP57/KAP1 recognize a methylated hexanucleotide to affect chromatin and DNA methylation of imprinting control regions. Molecular Cell 44 361-372. (https://doi. org/10.1016/j.molcel.2011.08.032)

Radford EJ, Ito M, Shi H, Corish JA, Yamazawa K, Isganaitis E, Seisenberger S, Hore TA, Reik W, Erkek S, et al. 2014 In utero effects in utero undernourishment perturbs the adult sperm methylome and intergenerational metabolism. Science 345 1255903. (https://doi. org/10.1126/science.1255903)

Ramsahoye BH, Biniszkiewicz D, Lyko F, Clark V, Bird AP \& Jaenisch R 2000 Non-CpG methylation is prevalent in embryonic stem cells and may be mediated by DNA methyltransferase 3a. PNAS 97 5237-5242. (https://doi.org/10.1073/pnas.97.10.5237)

Rando OJ 2016 Intergenerational transfer of epigenetic information in sperm. Cold Spring Harbor Perspectives in Medicine 6 a022988. (https:// doi.org/10.1101/cshperspect.a022988)

Ro S, Park C, Sanders KM, McCarrey JR \& Yan W 2007 Cloning and expression profiling of testis-expressed microRNAs. Developmental Biology 311 592-602. (https://doi.org/10.1016/j.ydbio.2007.09.009)

Saitou M, Kagiwada S \& Kurimoto K 2012 Epigenetic reprogramming in mouse pre-implantation development and primordial germ cells. Development 139 15-31. (https://doi.org/10.1242/dev.050849)

Sandoval J, Heyn H, Moran S, Serra-Musach J, Pujana MA, Bibikova M \& Esteller M 2011 Validation of a DNA methylation microarray for 450,000 CpG sites in the human genome. Epigenetics 6 692-702. (https://doi.org/10.4161/epi.6.6.16196)

Santos F, Hendrich B, Reik W \& Dean W 2002 Dynamic reprogramming of DNA methylation in the early mouse embryo. Developmental Biology 241 172-182. (https://doi.org/10.1006/dbio.2001.0501)

Saxonov S, Berg P \& Brutlag DL 2006 A genome-wide analysis of CpG dinucleotides in the human genome distinguishes two distinct classes of promoters. PNAS 103 1412-1417. (https://doi.org/10.1073/ pnas.0510310103)

Schultz DC, Friedman JR \& Rauscher FJ 3rd 2001 Targeting histone deacetylase complexes via KRAB-zinc finger proteins: the PHD and bromodomains of KAP-1 form a cooperative unit that recruits a novel isoform of the Mi-2alpha subunit of NuRD. Genes and Development 15 428-443. (https://doi.org/10.1101/gad.869501)

Seisenberger S, Andrews S, Krueger F, Arand J, Walter J, Santos F, Popp C, Thienpont B, Dean W \& Reik W 2012 The dynamics of genomewide DNA methylation reprogramming in mouse primordial germ cells. Molecular Cell 48 849-862. (https://doi.org/10.1016/j. molcel.2012.11.001)

Shalem O, Sanjana NE \& Zhang F 2015 High-throughput functional genomics using CRISPR-Cas9. Nature Reviews Genetics 16 299-311. (https://doi.org/10.1038/nrg3899)

Sharif J, Muto M, Takebayashi S, Suetake I, Iwamatsu A, Endo TA, Shinga J, Mizutani-Koseki Y, Toyoda T, Okamura K, et al. 2007 The
SRA protein Np95 mediates epigenetic inheritance by recruiting Dnmt1 to methylated DNA. Nature 450 908-912. (https://doi. org/10.1038/nature06397)

Sharma U, Conine CC, Shea JM, Boskovic A, Derr AG, Bing XY, Belleannee C, Kucukural A, Serra RW, Sun F, et al. 2016 Biogenesis and function of tRNA fragments during sperm maturation and fertilization in mammals. Science 351 391-396. (https://doi. org/10.1126/science.aad6780)

Shea JM, Serra RW, Carone BR, Shulha HP, Kucukural A, Ziller MJ, Vallaster MP, Gu H, Tapper AR, Gardner PD, et al. 2015 Genetic and epigenetic variation, but not diet, shape the sperm methylome. Developmental Cell 35 750-758. (https://doi.org/10.1016/j. devcel.2015.11.024)

Shen L, Inoue A, He J, Liu Y, Lu F \& Zhang Y 2014 Tet3 and DNA replication mediate demethylation of both the maternal and paternal genomes in mouse zygotes. Cell Stem Cell 15 459-470. (https://doi.org/10.1016/j.stem.2014.09.002)

Shirakata Y, Hiradate Y, Inoue H, Sato E \& Tanemura K 2014 Histone h4 modification during mouse spermatogenesis. Journal of Reproduction and Development 60 383-387. (https://doi.org/10.1262/ jrd.2014-018)

Singh P, Li AX, Tran DA, Oates N, Kang ER, Wu X \& Szabo PE 2013 De novo DNA methylation in the male germ line occurs by default but is excluded at sites of H3K4 methylation. Cell Reports 4 205-219. (https://doi.org/10.1016/j.celrep.2013.06.004)

Smallwood SA, Tomizawa S, Krueger F, Ruf N, Carli N, SegondsPichon A, Sato S, Hata K, Andrews SR \& Kelsey G 2011 Dynamic CpG island methylation landscape in oocytes and preimplantation embryos. Nature Genetics 43 811-814. (https://doi.org/10.1038/ ng.864)

Smith ZD, Chan MM, Mikkelsen TS, Gu H, Gnirke A, Regev A \& Meissner A 2012 A unique regulatory phase of DNA methylation in the early mammalian embryo. Nature 484 339-344. (https://doi. org/10.1038/nature10960)

Smith ZD, Chan MM, Humm KC, Karnik R, Mekhoubad S, Regev A, Eggan K \& Meissner A 2014 DNA methylation dynamics of the human preimplantation embryo. Nature 511 611-615. (https://doi. org/10.1038/nature13581)

Song N, Liu J, An S, Nishino T, Hishikawa Y \& Koji T 2011 Immunohistochemical analysis of histone $\mathrm{H} 3$ modifications in germ cells during mouse spermatogenesis. Acta Histochemica et Cytochemica 44 183-190. (https://doi.org/10.1267/ahc.11027)

Soubry A, Hoyo C, Jirtle RL \& Murphy SK 2014 A paternal environmental legacy: evidence for epigenetic inheritance through the male germ line. Bioessays 36 359-371. (https://doi.org/10.1002/ bies.201300113)

Soubry A, Schildkraut JM, Murtha A, Wang F, Huang Z, Bernal A, Kurtzberg J, Jirtle RL, Murphy SK \& Hoyo C 2013 Paternal obesity is associated with IGF2 hypomethylation in newborns: results from a Newborn Epigenetics Study (NEST) cohort. BMC Medicine 1129. (https://doi.org/10.1186/1741-7015-11-29)

Soubry A, Murphy SK, Wang F, Huang Z, Vidal AC, Fuemmeler BF, Kurtzberg J, Murtha A, Jirtle RL, Schildkraut JM, et al. 2015 Newborns of obese parents have altered DNA methylation patterns at imprinted genes. International Journal of Obesity 39 650-657. (https://doi.org/10.1038/ijo.2013.193)

Stegemann R \& Buchner DA 2015 Transgenerational inheritance of metabolic disease. Seminars in Cell and Developmental Biology 43 131-140. (https://doi.org/10.1016/j.semcdb.2015.04.007)

Stepper P, Kungulovski G, Jurkowska RZ, Chandra T, Krueger F, Reinhardt R, Reik W, Jeltsch A \& Jurkowski TP 2017 Efficient targeted DNA methylation with chimeric dCas9-Dnmt3a-Dnmt3L methyltransferase. Nucleic Acids Research 45 1703-1713. (https://doi. org/10.1093/nar/gkw1112)

Strogantsev R, Krueger F, Yamazawa K, Shi H, Gould P, GoldmanRoberts M, McEwen K, Sun B, Pedersen R \& Ferguson-Smith AC 2015
(C) 2018 Society for Endocrinology Published by Bioscientifica Ltd. Printed in Great Britain 
Allele-specific binding of ZFP57 in the epigenetic regulation of imprinted and non-imprinted monoallelic expression. Genome Biology 16 112. (https://doi.org/10.1186/s13059-015-0672-7)

Takai D \& Jones PA 2004 Origins of bidirectional promoters: computational analyses of intergenic distance in the human genome. Molecular Biology and Evolution 21 463-467. (https://doi. org $/ 10.1093 / \mathrm{molbev} / \mathrm{msh} 040$ )

Tan X, Xu X, Elkenani M, Smorag L, Zechner U, Nolte J, Engel W \& Pantakani DV 2013 Zfp819, a novel KRAB-zinc finger protein, interacts with KAP1 and functions in genomic integrity maintenance of mouse embryonic stem cells. Stem Cell Research 11 1045-1059. (https://doi.org/10.1016/j.scr.2013.07.006)

Tang WW, Dietmann S, Irie N, Leitch HG, Floros VI, Bradshaw CR, Hackett JA, Chinnery PF \& Surani MA 2015 A unique gene regulatory network resets the human germline epigenome for development. Cell 161 1453-1467. (https://doi.org/10.1016/j. cell.2015.04.053)

Tang WW, Kobayashi T, Irie N, Dietmann S \& Surani MA 2016 Specification and epigenetic programming of the human germ line. Nature Reviews Genetics 17 585-600. (https://doi.org/10.1038/ nrg.2016.88)

Tirado-Magallanes R, Rebbani K, Lim R, Pradhan S \& Benoukraf T 2017 Whole genome DNA methylation: beyond genes silencing. Oncotarget 8 5629-5637.

Tomizawa S, Kobayashi H, Watanabe T, Andrews S, Hata K, Kelsey G \& Sasaki H 2011 Dynamic stage-specific changes in imprinted differentially methylated regions during early mammalian development and prevalence of non-CpG methylation in oocytes. Development 138 811-820. (https://doi.org/10.1242/dev.061416)

Tseng YT, Liao HF, Yu CY, Mo CF \& Lin SP 2015 Epigenetic factors in the regulation of prospermatogonia and spermatogonial stem cells. Reproduction 150 R77-R91. (https://doi.org/10.1530/REP-15-0100)

Vasicek TJ, Zeng L, Guan XJ, Zhang T, Costantini F \& Tilghman SM 1997 Two dominant mutations in the mouse fused gene are the result of transposon insertions. Genetics 147 777-786.

Vojta A, Dobrinic P, Tadic V, Bockor L, Korac P, Julg B, Klasic M \& Zoldos V 2016 Repurposing the CRISPR-Cas9 system for targeted DNA methylation. Nucleic Acids Research 44 5615-5628. (https://doi. org/10.1093/nar/gkw159)

Voon HP \& Gibbons RJ 2016 Maintaining memory of silencing at imprinted differentially methylated regions. Cellular and Molecular Life Sciences: CMLS 73 1871-1879. (https://doi.org/10.1007/s00018016-2157-6)

Wang L, Zhang J, Duan J, Gao X, Zhu W, Lu X, Yang L, Li G, Ci W, Li W, et al. 2014 Programming and inheritance of parental DNA methylomes in mammals. Cell 157 979-991. (https://doi. org/10.1016/j.cell.2014.04.017)

Waterland RA, Dolinoy DC, Lin JR, Smith CA, Shi X \& Tahiliani KG 2006 Maternal methyl supplements increase offspring DNA methylation at Axin fused. Genesis 44 401-406. (https://doi. org/10.1002/dvg.20230)

Weber M, Hellmann I, Stadler MB, Ramos L, Paabo S, Rebhan M \& Schubeler D 2007 Distribution silencing potential and evolutionary impact of promoter DNA methylation in the human genome. Nature Genetics 39 457-466. (https://doi.org/10.1038/ng1990)

Wei Y, Yang CR, Wei YP, Zhao ZA, Hou Y, Schatten H \& Sun QY 2014 Paternally induced transgenerational inheritance of susceptibility to diabetes in mammals. PNAS 111 1873-1878. (https://doi. org/10.1073/pnas.1321195111)
Wei Y, Schatten H \& Sun QY 2015 Environmental epigenetic inheritance through gametes and implications for human reproduction. Human Reproduction Update 21 194-208. (https://doi.org/10.1093/humupd/ dmu061)

Wolf G, Yang P, Fuchtbauer AC, Fuchtbauer EM, Silva AM, Park C, Wu W, Nielsen AL, Pedersen FS \& Macfarlan TS 2015 The KRAB zinc finger protein ZFP809 is required to initiate epigenetic silencing of endogenous retroviruses. Genes and Development 29 538-554. (https://doi.org/10.1101/gad.252767.114)

Wossidlo M, Nakamura T, Lepikhov K, Marques CJ, Zakhartchenko V, Boiani M, Arand J, Nakano T, Reik W \& Walter J 2011 5 -Hydroxymethylcytosine in the mammalian zygote is linked with epigenetic reprogramming. Nature Communications 2 241. (https:// doi.org/10.1038/ncomms1240)

Wu Q \& Suzuki M 2006 Parental obesity and overweight affect the body-fat accumulation in the offspring: the possible effect of a highfat diet through epigenetic inheritance. Obesity Reviews 7 201-208. (https://doi.org/10.1111/j.1467-789X.2006.00232.x)

Wu H \& Zhang Y 2014 Reversing DNA methylation: mechanisms, genomics, and biological functions. Cell 156 45-68. (https://doi. org/10.1016/j.cell.2013.12.019)

Xie W, Barr CL, Kim A, Yue F, Lee AY, Eubanks J, Dempster EL \& Ren B 2012 Base-resolution analyses of sequence and parent-of-origin dependent DNA methylation in the mouse genome. Cell 148 816-831. (https://doi.org/10.1016/j.cell.2011.12.035)

Yamaguchi S, Hong K, Liu R, Shen L, Inoue A, Diep D, Zhang K \& Zhang Y 2012 Tet1 controls meiosis by regulating meiotic gene expression. Nature 492 443-447. (https://doi.org/10.1038/ nature11709)

Yamaguchi S, Hong K, Liu R, Inoue A, Shen L, Zhang K \& Zhang Y 2013a Dynamics of 5-methylcytosine and 5-hydroxymethylcytosine during germ cell reprogramming. Cell Research 23 329-339. (https:// doi.org/10.1038/cr.2013.22)

Yamaguchi S, Shen L, Liu Y, Sendler D \& Zhang Y 2013b Role of Tet1 in erasure of genomic imprinting. Nature $\mathbf{5 0 4} 460-464$. (https://doi. org/10.1038/nature12805)

Yan N, Lu Y, Sun H, Tao D, Zhang S, Liu W \& Ma Y 2007 A microarray for microRNA profiling in mouse testis tissues. Reproduction 134 73-79. (https://doi.org/10.1530/REP-07-0056)

Yan J, Zierath JR \& Barres R 2011 Evidence for non-CpG methylation in mammals. Experimental Cell Research 317 2555-2561. (https://doi. org/10.1016/j.yexcr.2011.08.019)

Yong WS, Hsu FM \& Chen PY 2016 Profiling genome-wide DNA methylation. Epigenetics and Chromatin 9 26. (https://doi. org/10.1186/s13072-016-0075-3)

Zhu C, Gao Y, Guo H, Xia B, Song J, Wu X, Zeng H, Kee K, Tang F \& Yi C 2017 Single-cell 5-formylcytosine landscapes of mammalian early embryos and ESCs at single-base resolution. Cell Stem Cell 20 720.e5-731.e5. (https://doi.org/10.1016/j.stem.2017.02.013)

Ziller MJ, Gu H, Muller F, Donaghey J, Tsai LT, Kohlbacher O, De Jager PL, Rosen ED, Bennett DA, Bernstein BE, et al. 2013 Charting a dynamic DNA methylation landscape of the human genome. Nature 500 477-481. (https://doi.org/10.1038/nature12433)

Zuo X, Sheng J, Lau HT, McDonald CM, Andrade M, Cullen DE, Bell FT, Iacovino M, Kyba M, Xu G, et al. 2012 Zinc finger protein ZFP57 requires its co-factor to recruit DNA methyltransferases and maintains DNA methylation imprint in embryonic stem cells via its transcriptional repression domain. Journal of Biological Chemistry $\mathbf{2 8 7}$ 2107-2118. (https://doi.org/10.1074/jbc.M111.322644)

Received in final form 28 November 2017

Accepted 4 December 2017

Accepted Preprint published online 4 December 2017 http://jme.endocrinology-journals.org https://doi.org/10.1530/JME-17-0189
(C) 2018 Society for Endocrinology Published by Bioscientifica Ltd. Printed in Great Britain 